\title{
The role of atomic oxygen concentration in the ionization balance of the lower ionosphere during solar proton events
}

\author{
A. Osepian ${ }^{1}$, V. Tereschenko ${ }^{1}$, P. Dalin ${ }^{2}$, and S. Kirkwood ${ }^{2}$ \\ ${ }^{1}$ Polar Geophysical Institute, Chalturuna 15, 183010 Murmansk, Russia \\ ${ }^{2}$ Swedish Institute of Space Physics, P.O. Box 812, 98128 Kiruna, Sweden
}

Received: 20 June 2007 - Revised: 7 December 2007 - Accepted: 17 December 2007 - Published: 4 February 2008

\begin{abstract}
The influence of atomic oxygen concentration on the height distribution of the main positive and negative ions and on electron density in the mesosphere is studied for the conditions prevailing during the solar proton event on 17 January 2005 . It is shown by numerical modeling that the electron and ion density profiles are strongly dependent on the choice of the atomic oxygen profile. Experimental measurements of the electron density are used as the criterion for choosing the atomic oxygen profile in the mesosphere. With the help of modeling, the atomic oxygen profile in the daytime in the winter mesosphere is found to lead to a model electron density profile best matching the electron density profile obtained experimentally. As a result, with the help of modeling, we find the atomic oxygen profiles at various solar zenith angles in the winter mesosphere which lead to model electron density profiles matching the electron density profiles obtained experimentally.

Alteration of the atomic oxygen concentration leads to a redistribution of the abundance of both positive and negative ion constituents, with changes in their total concentrations and transition heights. In consequence this results in changes of the electron density and effective recombination coefficient. For conditions of low concentration of atomic oxygen (during a solar proton event), the formation of cluster ions is the key process determining electron and ion densities at altitudes up to $77 \mathrm{~km}$. The complex negative $\mathrm{CO}_{3}^{-}$ion is formed up to about $74 \mathrm{~km}$ and the final $\mathrm{NO}_{3}^{-}$ion, which is stable in relation to the atomic oxygen, is the dominant negative ion up to $74 \mathrm{~km}$. As a result the transition heights between cluster ions and molecular ions and between negative ions and electron density are located at $77 \mathrm{~km}$ and $66 \mathrm{~km}$, respectively.
\end{abstract}

Correspondence to: P. Dalin

(pdalin@irf.se)
Keywords. Ionosphere (Ion chemistry and composition; Polar ionosphere) - Atmospheric composition and structure (Middle atmosphere - composition and chemistry)

\section{Introduction}

Studies of the lower ionosphere and mesosphere are complicated by a number of problems, both experimental and theoretical. One of the main experimental problems is poor accessibility of in-situ measurements. Present knowledge on ion composition is based on only a limited number of sounding rocket flights.

Electron concentration is mainly measured with different ground-based techniques, although occasional measurements are made using sounding rockets. It is often extremely difficult to measure electron concentration in the mesosphere with a good precision, particularly by ground-based techniques, because of the low values of electron density, especially during nighttime. However, in the presence of extra ionization in the lower ionosphere, produced by precipitating particles or solar X-ray flares, the electron concentration can be measured more easily.

The electron concentration in the polar D-region is extremely variable, especially during geomagnetic disturbances. Moreover, even during quiet periods, electron density profiles measured for similar conditions (for example, the same season, the same zenith angle) can sometimes differ substantially. This means that, not only the changeable ionization sources, but also a set of other factors, such as changes in concentration of minor neutral species and neutral atmosphere temperature, are important for the formation of electron density profiles.

Published by Copernicus Publications on behalf of the European Geosciences Union. 
The large variability of the height profile of electron concentration, $N_{e}(h)$, in the polar lower ionosphere is the reason why there is no reliable empirical model of the high-latitude D-region yet available which can be used in the absence of direct measurements. The empirical models developed by Friedrich et al. (2006) and McKinnell and Friedrich (2007), require the availability of riometer measurements, and still cannot predict electron density at $70 \mathrm{~km}$ height under all conditions to better than an order of magnitude. A useful theoretical model must be capable of describing the $N_{e}(h)$ dependence on all the factors influencing the electron density.

Theoretical studies provide major advances for our understanding of the processes controlling the ion composition and electron density in the lower ionosphere. In a theoretical study, the physical and chemical processes, which produce and maintain the lower ionosphere, such as ionization by different sources (solar electromagnetic radiation in different wavelength ranges, galactic cosmic rays and high energy particles), recombination laws, photodissociation and photodetachment, formations of different ions, which are described by ion-chemical reactions, and main ionic transformation processes and their dependencies on neutral temperature and density, humidity and the concentrations of minor neutral species etc., have to be taken into account. Ion composition and ion chemical reactions in the D-region are, for example, directly coupled to the local concentration of longlived species such as $\mathrm{O}, \mathrm{NO}, \mathrm{H}_{2} \mathrm{O}$.

In this study, based on a theoretical model of the D-region (Smirnova et al., 1988; Kirkwood and Osepian, 1995; Osepian and Smirnova, 1997), we investigate the influence of the atomic oxygen concentration on the ionization balance at mesospheric altitudes during a solar proton event (SPE) that occurred on 17 January 2005.

At the present time there is a great deficiency of experimental knowledge on the atomic oxygen concentration at altitudes of the lower ionosphere. Rocket measurements (Dickinson et al., 1980; Gumbel et al., 1998) are available but they are of sporadic character and therefore do not reflect all the geophysical situations. Due to the poor availability of experimental data on the atomic oxygen concentration [O] below $80 \mathrm{~km}$, theoretical [O] $(h)$-profiles estimated at mesospheric altitudes with different diffusive-photochemical models are used.

Variations between such estimates are rather large. Therefore one of the major requirements throughout the middle atmosphere is information on the $[\mathrm{O}](h)$-profiles under different geophysical situations so that they can be incorporated into theoretical models. In this study we use experimental data on electron density in the lower ionosphere obtained with two ground-based techniques, namely incoherent scatter of radio waves (see e.g. Nygrén, 1996) using the EISCAT $224 \mathrm{MHz}$ radar in Troms $\varnothing$, Norway (geographical coordinates are $\varphi=69.6^{\circ}, \lambda=19.3^{\circ}$; geomagnetic coordinates are $\Phi=66.2^{\circ}, \Lambda=105.8^{\circ}$ ), and the partial reflection of radiowaves using a $2.8 \mathrm{MHz}$ radar in Murmansk, Russia (geographical coordinates are $\varphi=69.0^{\circ}, \lambda=33.0^{\circ}$; geomagnetic coordinates are $\Phi=64.5^{\circ}, \Lambda=115.0^{\circ}$ ). We combine observations with a theoretical ionization-recombination model to determine the correct choice of the atomic oxygen profile in the mesosphere during the SPE in the winter season.

In Sect. 2 we consider available theoretical results on the height distribution of atomic oxygen obtained with different diffusive-photochemical models during both quiet and disturbed periods.

In Sect. 3 we estimate the effective loss coefficients of the primary ions, $\mathrm{NO}^{+}$and $\mathrm{O}_{2}^{+}$, in relation to the formation of hydrated ion clusters as well as the loss rate of the primary ions $\mathrm{O}_{2}^{-}$in relation to the formation of complex negative ions. We use an ion-chemical model of the D-region and theoretical $[\mathrm{O}](h)$-profiles with maximum and minimum values. We also estimate the effective rate coefficients for competing processes affecting $\mathrm{NO}^{+}, \mathrm{O}_{2}^{+}$and $\mathrm{O}_{2}^{-}$loss in reactions with atomic oxygen. Comparison of these effective rate coefficients for a given $[\mathrm{O}]$ concentration allows us to understand the importance of reactions with atomic oxygen in the ionization balance at each altitude, and in the formation of electron density and effective recombination profiles.

In Sect. 4 we compare experimental $\mathrm{N}(h)$-profiles observed during SPE with $\mathrm{N}(h)$-profiles calculated using different $[\mathrm{O}](h)$-profiles.

\section{Models of atomic oxygen}

Solar ultraviolet radiation is chiefly absorbed by molecular oxygen $\left(\mathrm{O}_{2}\right)$ which is photodissociated to produce two oxygen atoms $(\mathrm{O})$ :

$\mathrm{O}_{2}+h v \rightarrow \mathrm{O}\left({ }^{3} \mathrm{P}\right)+\mathrm{O}\left({ }^{1} \mathrm{D}\right)$

The thermospheric production of odd oxygen produces a downward flux of atomic oxygen which must be balanced by destructive processes occurring at lower altitudes. Atomic oxygen disappears via the following reactions (Anderson, 1976):

$$
\begin{aligned}
& \mathrm{O}\left({ }^{3} \mathrm{P}\right)+\mathrm{O}\left({ }^{3} \mathrm{P}\right)+\mathrm{M} \rightarrow \mathrm{O}_{2}+\mathrm{M} \\
& \mathrm{O}\left({ }^{3} \mathrm{P}\right)+\mathrm{O}_{2}+\mathrm{N}_{2} \rightarrow \mathrm{O}_{3}+\mathrm{N}_{2} \\
& \mathrm{O}\left({ }^{3} \mathrm{P}\right)+\mathrm{O}_{3} \rightarrow \mathrm{O}_{2}+\mathrm{O}_{2} \\
& \mathrm{O}\left({ }^{1} \mathrm{D}\right)+\mathrm{O}_{3} \rightarrow \mathrm{O}_{2}+\mathrm{O}_{2} \\
& \mathrm{O}\left({ }^{1} \mathrm{D}\right)+\mathrm{O}_{3} \rightarrow \mathrm{O}_{2}+\mathrm{O}\left({ }^{3} \mathrm{P}\right)+\mathrm{O}\left({ }^{3} \mathrm{P}\right) \\
& \mathrm{O}\left({ }^{1} \mathrm{D}\right)+\mathrm{N}_{2} \rightarrow \mathrm{O}\left({ }^{3} \mathrm{P}\right)+\mathrm{N}_{2}
\end{aligned}
$$

where $\mathrm{M}$ is an atmospheric molecule, either $\mathrm{O}_{2}$ or $\mathrm{N}_{2}$, acting as a third body. 
The peak of $[\mathrm{O}]$-concentration $\left(\approx 10^{11}-10^{12} \mathrm{~cm}^{-3}\right)$ is generally located at around $95 \mathrm{~km}$ height. Below $90 \mathrm{~km}$ the influence of fast reacting hydrogen species becomes significant for odd oxygen loss:

$$
\begin{aligned}
& \mathrm{H}+\mathrm{O}_{3} \rightarrow \mathrm{OH}+\mathrm{O}_{2} \\
& \mathrm{H}+\mathrm{O}_{2}+\mathrm{M} \rightarrow \mathrm{HO}_{2}+\mathrm{M} \\
& \mathrm{OH}+\mathrm{O}\left({ }^{3} \mathrm{P}\right) \rightarrow \mathrm{H}+\mathrm{O}_{2} \\
& \mathrm{HO}_{2}+\mathrm{O}\left({ }^{3} \mathrm{P}\right) \rightarrow \mathrm{OH}+\mathrm{O}_{2}
\end{aligned}
$$

In the upper atmosphere both vertical and horizontal transport of atomic oxygen is important. Since the lifetime of atomic oxygen above the mesopause is large, the average meridional flow transports atomic oxygen from the summer hemisphere to the winter hemisphere, where it is destroyed by recombination. Here species such as $\mathrm{O}$ and $\mathrm{NO}$ are transported downward. Turbulent diffusion resulting from the breaking of gravity waves acts as a transport mechanism responsible for strong mixing and dissipative processes. Thus the atomic oxygen is strongly controlled by both photochemical and dynamical processes (downward and meridional transports, turbulence, molecular and eddy diffusions) (Shimazaki and Laird, 1972; Keneshea et al., 1972; Thomas and Bowman, 1972; Maharaj-Sharma and Shepherd, 2004; Russell et al., 2004, 2005; Murray and Plane, 2005). These processes are expected to lead to substantial changes in the atomic oxygen concentration. As a result, available diffusive-photochemical models give estimates of the [O]concentration, which differ significantly between the different models.

Examples of theoretical $\mathrm{O}(h)$-profiles $(\mathrm{O}(h)$-profiles 1 and 2 ) are presented in Fig. 1. These profiles reflect the minimum and maximum values of $[\mathrm{O}]$ given by different diffusivephotochemical models for daytime quiet conditions. The $\mathrm{O}(h)$-profile number 1 is taken from the model by Shimazaki and Laird (1972). The $\mathrm{O}(h)$-profile 2 at altitudes less than $80 \mathrm{~km}$ is taken from the model by Zadorozhny (1982) and at altitudes above $80 \mathrm{~km}$ from the MSIS-2000 neutral atmosphere model (Hedin, 1991). Differences in the concentration of atomic oxygen between O-profiles 1 and 2 are about an order of the magnitude. As has been mentioned above, these differences are due to differences in accounting for dynamical processes, in model values of eddy diffusion coefficient, in concentration of ozone and other species, in solar radiation intensity at different wavelength ranges, in absorption cross sections and in other factors applied in the model studies. For example, according to the model calculations by Keneshea et al. (1972), a change of the turbulent diffusion coefficient by a factor of 3 leads to an order of magnitude change in $[\mathrm{O}]$-concentration.

It is well known that, under conditions of strong and long duration disturbances (SPE), there is both a large increase in ionization and changes of the neutral composition (Porter et

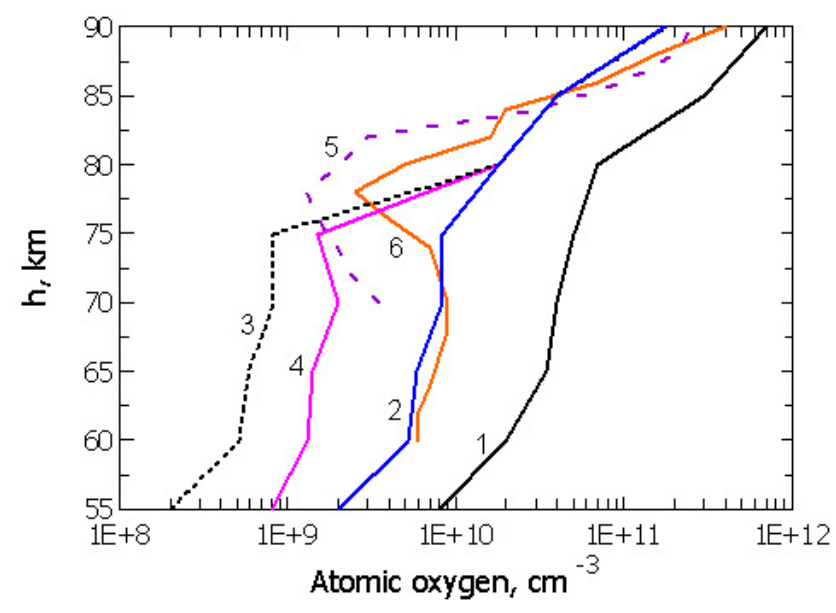

Fig. 1. Atomic oxygen profiles in the mesosphere. 1-5 are model profiles. 1 is from Shimazaki and Laird (1972); 2 is from Zadorozhny (1982); 3 and 4 are assumed for SPE conditions in the present study; 5 is for summer, noctilucent cloud conditions (Murray and Plane, 2005). Profile 6 corresponds to measurements for summer noctilucent cloud conditions (Dickinson et al., 1980).

al., 1976; Solomon et al., 1981, 1983; McPeters and Jackman, 1985; Reid et al., 1991; Zadorozhny et al., 1992; Jackman et al., 1995, 2005; Seppala et al., 2004; Rochen et al., 2005; Verronen et al., 2005; Lopez-Puertas et al., 2005). One of the important effects of particle precipitation events is enhanced concentration of nitric oxide, NO, and of odd hydrogen constituents, $\mathrm{H}$ and $\mathrm{OH}$. The latter can arise from Reactions (11-13) and dissociative recombination (14) of water cluster ions $\mathrm{H}^{+} .\left(\mathrm{H}_{2} \mathrm{O}\right)_{n}$ (Frederick, 1976; Porter et al., 1976; Reid et al., 1977; Solomon et al., 1981):

$\mathrm{O}_{2}^{+} \cdot \mathrm{H}_{2} \mathrm{O}+\mathrm{H}_{2} \mathrm{O} \rightarrow \mathrm{H}_{3} \mathrm{O}^{+} . \mathrm{OH}+\mathrm{O}_{2}$

$\mathrm{O}_{2}^{+} \cdot \mathrm{H}_{2} \mathrm{O}+\mathrm{H}_{2} \mathrm{O} \rightarrow \mathrm{H}_{3} \mathrm{O}^{+}+\mathrm{OH}+\mathrm{O}_{2}$

$\mathrm{H}_{3} \mathrm{O}^{+} . \mathrm{OH}+\mathrm{H}_{2} \mathrm{O} \rightarrow \mathrm{H}^{+} .\left(\mathrm{H}_{2} \mathrm{O}\right)_{2}+\mathrm{OH}$

$\mathrm{H}^{+}\left(\mathrm{H}_{2} \mathrm{O}\right)_{n}+e \rightarrow \mathrm{H}+n\left(\mathrm{H}_{2} \mathrm{O}\right)$

According to photo-chemical models (Swider and Keneshea, 1973; Frederick, 1976; Heath et al., 1977; Solomon et al., 1983; Kozlov et al., 1988; Smirnova et al., 1990; Jackman et al., 1995; Verronen et al., 2005) an increase of $\mathrm{H}$ and $\mathrm{OH}-$ concentration leads to changes in the oxygen constituents in the mesosphere. The details of the neutral oxygen component variations under the effects of very strong solar proton precipitation depend on height, season, solar illumination and intensity of the ionization source. Theoretical estimates (Swider and Keneshea, 1973; Smirnova et al., 1990) show that the $[\mathrm{O}]$-concentration can decrease in the daytime by a factor of $2-8$ at altitudes $50-75 \mathrm{~km}$ due to increasing $[\mathrm{OH}]$ and $\left[\mathrm{HO}_{2}\right]$-concentrations and increasing rates of Reactions (9) and (10). 
In accordance with these theoretical estimates we have decreased the atomic oxygen concentration by factors of 10 and 4 at altitudes of $50-75 \mathrm{~km}$ relative to the O-profile 2 deduced for quiet conditions as seen in Fig. 1 (O-profiles 3 and 4). We use these hypothetical O-profiles 3 and 4, together with the O-profiles 1 and 2, as input to a theoretical model for estimation of the effective loss rate coefficients of the primary ions $\mathrm{NO}^{+}, \mathrm{O}_{2}^{+}, \mathrm{O}_{2}^{-}$and for calculation of the ion composition, electron density and effective recombination coefficient profiles.

In Fig. 1 we also present two further O-profiles, (5) as modeled by Murray and Plane (2005) and (6) as measured by Dickinson et al. (1980), both for the summer mesosphere. In these cases the observed sharp depletion in $\mathrm{O}$ concentration can be explained by an enhancement of $\mathrm{H}, \mathrm{OH}, \mathrm{HO}_{2}$, $\mathrm{H}_{2} \mathrm{O}_{2}$ related to the presence of noctilucent clouds (Murray and Plane, 2005). The source of hydrogen compounds is not the same as during a solar proton event, but the effects are similar to those we have assumed in profiles 3 and 4 .

\section{Influence of atomic oxygen concentration on ion com- position and electron density}

To investigate the role of the atomic oxygen concentration in the formation of ion composition and electron density profiles at mesospheric altitudes, we use a theoretical scheme describing the main ionic transformation processes and ionchemical reactions (Smirnova et al., 1988) which forms the basis of the theoretical model applied in the present study. The scheme is shown in the Appendix. Complex transformations and formation of hydrated ion clusters are via the following reaction chains:

$\mathrm{O}_{2}^{+} \rightarrow \mathrm{O}_{4}^{+} \rightarrow \mathrm{O}_{2}^{+} \cdot\left(\mathrm{H}_{2} \mathrm{O}\right)_{n} \rightarrow \mathrm{H}^{+}\left(\mathrm{H}_{2} \mathrm{O}\right)_{n}$

$\mathrm{NO}^{+} \rightarrow \mathrm{NO}^{+} .\left(\mathrm{H}_{2} \mathrm{O}\right)_{n} \rightarrow \mathrm{H}^{+} .\left(\mathrm{H}_{2} \mathrm{O}\right)_{n}$

and formation of intermediate negative ions is represented by the following chains:

$\mathrm{O}_{2}^{-} \rightarrow \mathrm{O}_{3}^{-}$and $\mathrm{O}_{4}^{-} \rightarrow \mathrm{CO}_{4}^{-}$and $\mathrm{CO}_{3}^{-} \rightarrow \mathrm{O}_{2}^{-}$

$\mathrm{O}^{-} \rightarrow \mathrm{O}_{3}^{-} \rightarrow \mathrm{CO}_{3}^{-} \rightarrow \mathrm{O}_{2}^{-} \rightarrow \mathrm{O}^{-}$

These are described by a large number of ion-chemical reactions in detailed reaction schemes. In the chemical model developed by Smirnova et al. (1988) the efficiencies of reactions included in the channels $(15 \mathrm{a}-\mathrm{d})$ are substituted by effective parameters: $\mathrm{B}\left(\mathrm{O}_{2}^{+}\right), \mathrm{B}\left(\mathrm{NO}^{+}\right), \mathrm{B}\left(\mathrm{O}_{2}^{-}\right), \mathrm{B}\left(\mathrm{O}^{-}\right)$and $\beta$.

They include the rate constants of the main ionic transformation processes and contain the dependencies on neutral temperature and density, humidity and the concentration of the minor neutral species. The reactions included in the theoretical scheme are presented in Tables 1-3 in the Appendix.
Computations of the ion composition and electron density have been made for the SPE on 17 January 2005 at 09:50 UT based on the O-profiles 1-4. For computation of ionization rates we use differential solar proton fluxes in the energy range $2.4-300 \mathrm{MeV}$ measured by the GOES-10 satellite (http://spidr.ngdc.noaa.gov/ spidr/). Ionization rates produced by both soft and hard $\mathrm{X}$-rays during a strong solar flare with maximum intensity $\left(j_{1}(\lambda=0.5-3.0 \AA)=9.2 \times 10^{-5} \mathrm{watt} / \mathrm{m}^{2}\right.$ and $j_{2}(\lambda=1.0$ $8.0 \AA)=4.1 \times 10^{-4}$ watt $/ \mathrm{m}^{2}$ ) at $09: 50 \mathrm{UT}$ on 17 January 2005 (http://www.ngdc.noaa.gov/stp/SOLAR/) have also been calculated and taken into account.

\subsection{The influence of atomic oxygen concentration on} positive-ion composition

In the theoretical scheme 1 (Smirnova et al., 1988), the intermediate cluster ions present in the reaction chains $(15 \mathrm{a}, \mathrm{b})$, in the form of $\mathrm{O}_{2}^{+} . \mathrm{X}$ and $\mathrm{NO}^{+} . \mathrm{X}$, with recombination coefficient $\alpha \sim 2 \times 10^{-6} \mathrm{~cm}^{3} \mathrm{~s}^{-1}$, are combined into a Cluster ${ }_{1}^{+}$ family $\left(\mathrm{CB}_{1}^{+}\right)$. They are formed from the primary ions $\mathrm{O}_{2}^{+}$and $\mathrm{NO}^{+}$. The efficiency $\mathrm{B}_{\mathrm{O} 2+}$ of the reaction path $\mathrm{O}_{2}^{+} \rightarrow \mathrm{CB}_{1}^{+}$is determined by the expression (A1) given in the Appendix. The efficiency $\mathrm{B}_{\mathrm{NO}}+$ of the channel $\mathrm{NO}^{+} \rightarrow \mathrm{CB}_{1}^{+}$ is determined by the expression (A2) given in the Appendix. The proton hydrates are combined into a Cluster ${ }_{2}^{+}$family $\left(\mathrm{CB}_{2}^{+}\right)$with $\alpha \sim 1 \times 10^{-5} \mathrm{~cm}^{3} \mathrm{~s}^{-1}$. They are formed from $\mathrm{CB}_{1}^{+}$with the effective rate $\beta$, which is given by the Eq. (A3) in the Appendix.

The efficiencies of the reaction path forming hydrated ion clusters from $\mathrm{O}_{2}^{+}$ions, calculated for the O-profiles 1-4 are given in the upper panel of Fig. 2. (We use B to denote the efficiency of all reaction paths for a particular ion together as in Eqs. (A1), (A2). We use $v_{e f}$ to denote the efficiency of individual reaction paths, e.g. for the efficiency of reaction path $\mathrm{O}_{4}^{+}+\mathrm{O} \rightarrow \mathrm{O}_{2}^{+}+\mathrm{O}_{3}, v_{e f}=k_{2}[\mathrm{O}]$, where $k_{2}$ is given in Table A2).

The efficiency of the Eq. (15a) channel, (for the $\left[\mathrm{H}_{2} \mathrm{O}\right]-$ concentration equal to $1 \times 10^{-6}[\mathrm{M}] \mathrm{cm}^{-3}$ ) mainly depends on the loss rate of the $\mathrm{O}_{4}^{+}$ion through the formation of the hydrated ion cluster $\mathrm{O}_{2}^{+}\left(\mathrm{H}_{2} \mathrm{O}\right)$ in the reaction:

$\mathrm{O}_{4}^{+}+\mathrm{H}_{2} \mathrm{O} \rightarrow \mathrm{O}_{2}^{+}\left(\mathrm{H}_{2} \mathrm{O}\right)+\mathrm{O}_{2}$

and in the competing reaction with atomic oxygen:

$\mathrm{O}_{4}^{+}+\mathrm{O} \rightarrow \mathrm{O}_{2}^{+}+\mathrm{O}_{3}$

Efficiencies of the Reactions (16a) and (16b) are compared in the lower panel of Fig. 2.

The efficiency of the Eq. (15b) channel can depend on the loss rate of the intermediate ion $\mathrm{NO}^{+}\left(\mathrm{H}_{2} \mathrm{O}\right)$ in the reaction:

$\mathrm{NO}^{+} .\left(\mathrm{H}_{2} \mathrm{O}\right)+\mathrm{H}_{2} \mathrm{O}+\mathrm{N}_{2} \rightarrow \mathrm{NO}^{+} .\left(\mathrm{H}_{2} \mathrm{O}\right)_{2}+\mathrm{N}_{2}$

and in the competing reaction with atomic oxygen (Swider, 1972; Aikin and Goldberg, 1973):

$\mathrm{NO}^{+} .\left(\mathrm{H}_{2} \mathrm{O}\right)+\mathrm{O} \rightarrow \mathrm{NO}_{2}^{+}+\mathrm{H}_{2} \mathrm{O}$ 

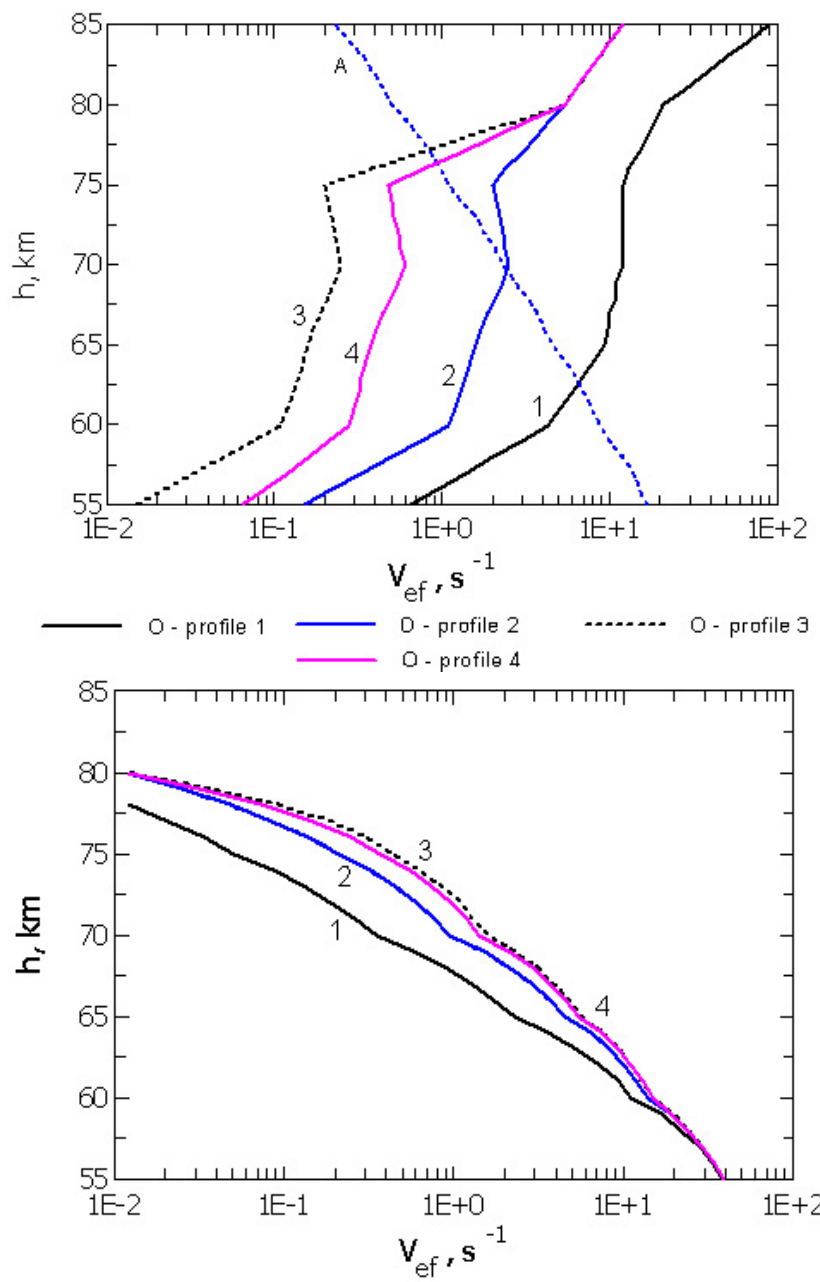

Fig. 2. Height profiles of reaction efficiencies. Upper panel: efficiencies of the reaction path forming hydrated ion clusters from $\mathrm{O}_{2}^{+}$ ion, The curves $1-4$ are efficiencies of the reaction of $\mathrm{O}_{4}^{+}$ions with atomic oxygen: $\mathrm{O}_{4}^{+}+\mathrm{O} \rightarrow \mathrm{O}_{2}^{+}+\mathrm{O}_{3}$, based on O-profiles 1-4.

Lower panel: curve $\mathrm{A}$ is the efficiency of hydrated ion formation $\mathrm{O}_{2}^{+}\left(\mathrm{H}_{2} \mathrm{O}\right)$ in the reaction: $\mathrm{O}_{4}^{+}+\mathrm{H}_{2} \mathrm{O} \rightarrow \mathrm{O}_{2}^{+}\left(\mathrm{H}_{2} \mathrm{O}\right)+\mathrm{O}_{2}$.

Efficiencies of the Reactions (17a, b) are compared in Fig. 3.

As it is seen from Figs. 2 and 3, the Reactions (16b) and (17b) lead to decreased efficiency or interruption of the chain of hydrated-ion-cluster formation at altitudes where there is a strong dependence on the atomic oxygen concentration. For example, when the $[\mathrm{O}]$-concentration decreases, the height, where the efficiencies of the Reactions (16a) and (16b) become equal increases from $h_{m}\left(\mathrm{CB}_{1}^{+}\right)=63 \mathrm{~km}$ (for O-profiles 1) to $h_{m}\left(\mathrm{CB}_{1}^{+}\right)=77-76 \mathrm{~km}$ (for O-profiles 3 and 4 ).

In Fig. 4 (upper panel) we show height profiles of the main positive ions based on calculations using O-profiles 1 and 4 during the SPE at 09:50 UT on 17 January 2005. It is clearly seen that changes of the [O]-concentration lead to

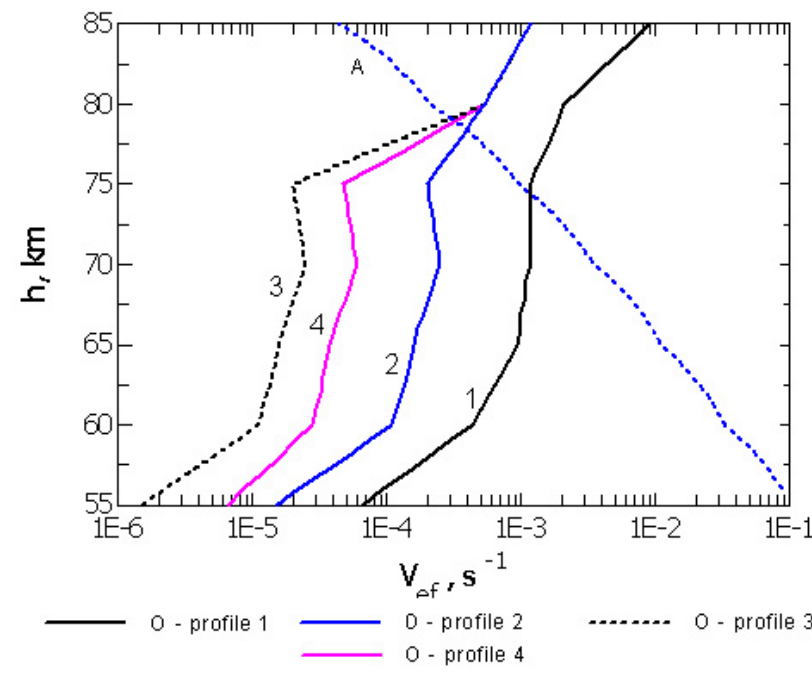

Fig. 3. Height profiles of reaction efficiencies. Curve A is efficiency of the reaction in which cluster $\mathrm{NO}^{+} .\left(\mathrm{H}_{2} \mathrm{O}\right)$ interacts with $\mathrm{H}_{2} \mathrm{O}: \mathrm{NO}^{+} .\left(\mathrm{H}_{2} \mathrm{O}\right)+\mathrm{H}_{2} \mathrm{O}+\mathrm{N}_{2} \rightarrow \mathrm{NO}^{+} .\left(\mathrm{H}_{2} \mathrm{O}\right)_{2}+\mathrm{N}_{2}$.

Curves 1-4 are efficiencies of the reaction in which cluster $\mathrm{NO}^{+} .\left(\mathrm{H}_{2} \mathrm{O}\right)$ interacts with atomic oxygen: $\mathrm{NO}^{+} .\left(\mathrm{H}_{2} \mathrm{O}\right)+\mathrm{O} \rightarrow \mathrm{NO}_{2}^{+}+\mathrm{H}_{2} \mathrm{O}$ based on O-profiles $1-4$.

a redistribution of the abundance of ion constituents in the whole height range. In the case of low [O]-concentration (O-profile 4), cluster ions dominate over simple molecular ions $\mathrm{NO}^{+}$and $\mathrm{O}_{2}^{+}$up to about $76-77 \mathrm{~km}$. It should be noted that under conditions of low [O], the concentration of the $\mathrm{CB}_{1}^{+}$cluster ion family is almost constant from 60 $77 \mathrm{~km}$ and then, above $77 \mathrm{~km}$, it decreases rapidly due to decreasing water vapor concentration. Cluster ions dominate only up to $72 \mathrm{~km}$ for high [O] (O-profile 1). Since the $(16 \mathrm{~b})$ reaction is much more effective under conditions of high [O]-concentration $\left(v_{e f}=2.8 \times 10^{-1} \mathrm{~s}^{-1}\right.$ at $60 \mathrm{~km}$, $v_{e f}=6.0 \times 10^{-1} \mathrm{~s}^{-1}$ at $70 \mathrm{~km}$ and $v_{e f}=7.8 \times 10^{-1} \mathrm{~s}^{-1}$ at $77 \mathrm{~km}$ - for O-profile 4; $v_{e f}=4.3 \mathrm{~s}^{-1}$ at $60 \mathrm{~km}, v_{e f}=1.2 \times 10^{1} \mathrm{~s}^{-1}$ at $70 \mathrm{~km}$ and $v_{e f}=1.4 \times 10^{1} \mathrm{~s}^{-1}$ at $77 \mathrm{~km}$ - for O-profile 1), in the model with low $[\mathrm{O}]$ concentration, the number of $\mathrm{O}_{2}^{+}$ions is much less than in the model with high $[\mathrm{O}]$. The concentration of $\mathrm{NO}^{+}$ions at the altitudes $68-80 \mathrm{~km}$ is also decreased both due to more active cluster formation and to a decrease in the rate of the charge exchange reaction:

$\mathrm{O}_{2}^{+}+\mathrm{NO} \rightarrow \mathrm{NO}^{+}+\mathrm{O}$

As a result, the magnitude of the $f^{+}$-parameter, describing the ratio of cluster ions to simple positive molecular ions, is increased in the model with low [O], as seen in the lower panel of Fig. 4. The transition height $h_{f+=1}$ describing the equity between the number density of clusters and simple molecular ions, is increased from $h_{f+=1}=72 \mathrm{~km}$ (for Oprofiles 1) to about $h_{f+=1}=76-77 \mathrm{~km}$ (for O-profiles 4 and $3)$. It is notable that decreases in [O] relative to O-profile 4 

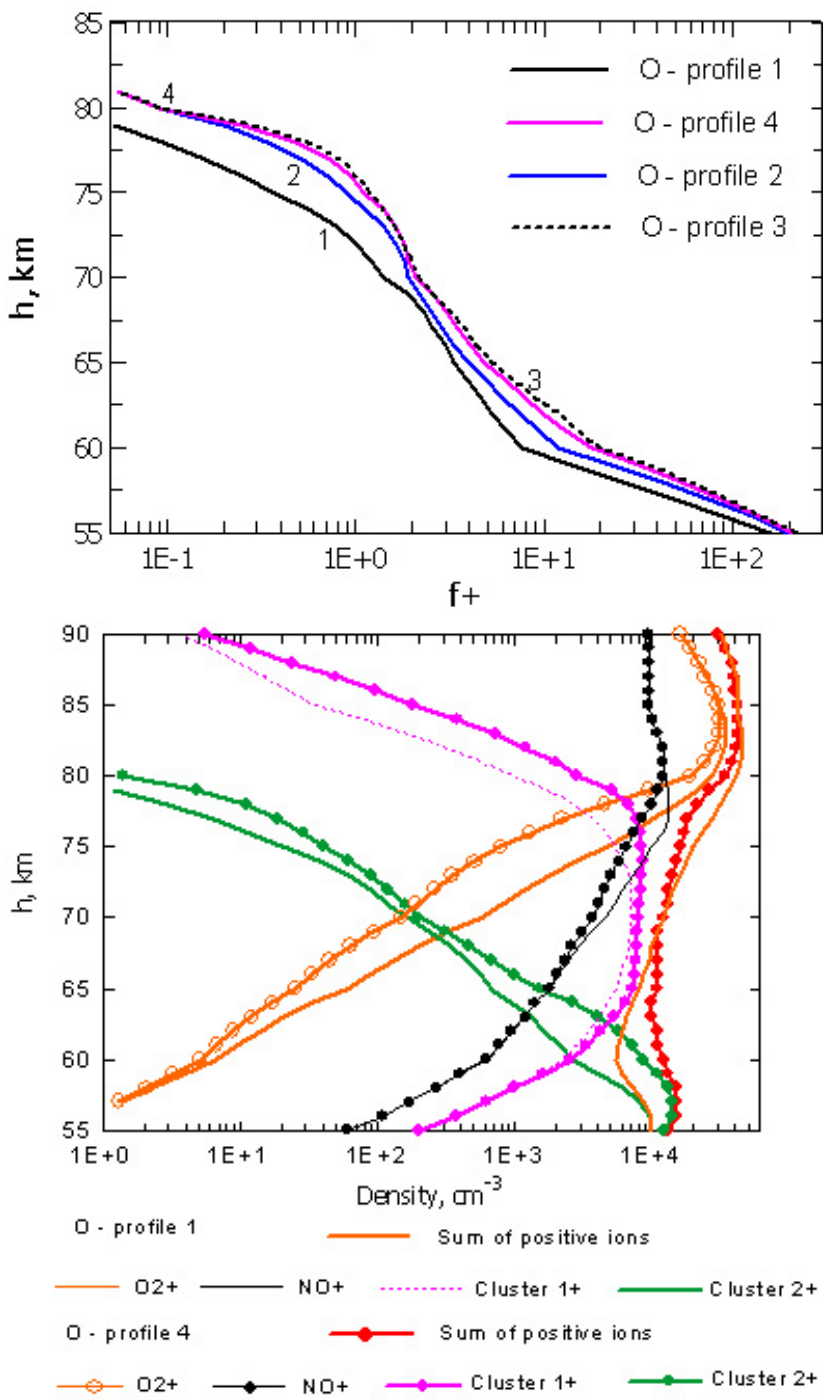

Fig. 4. Upper panel: Profiles of positive ions based on O-profiles 1 and 4 for 17 January 2005 at 09:50 UT. Lower panel: $f^{+}(h)$ profiles based on O-profiles 1-4 for 17 January 2005 at 09:50 UT.

(i.e. O-profile 3), do not alter the $f^{+}$-parameter or $h_{f+=1}$ noticeably. The total concentration of positive ions is decreased at altitudes $72-82 \mathrm{~km}$ in the model with low [O]. The $\mathrm{O}_{2}^{+}$ion is the major ion at heights above $80 \mathrm{~km}$.

3.2 The influence of atomic oxygen concentration on negative-ion composition

The primary $\mathrm{O}_{2}^{-}$and $\mathrm{O}^{-}$ions are formed in the reactions:

$\mathrm{O}_{2}+\mathrm{O}_{2}+e \rightarrow \mathrm{O}_{2}^{-}+\mathrm{O}_{2}$

$\mathrm{O}_{2}+\mathrm{N}_{2}+e \rightarrow \mathrm{O}_{2}^{-}+\mathrm{N}_{2}$

$\mathrm{O}_{3}+e \rightarrow \mathrm{O}^{-}+\mathrm{O}_{2}$

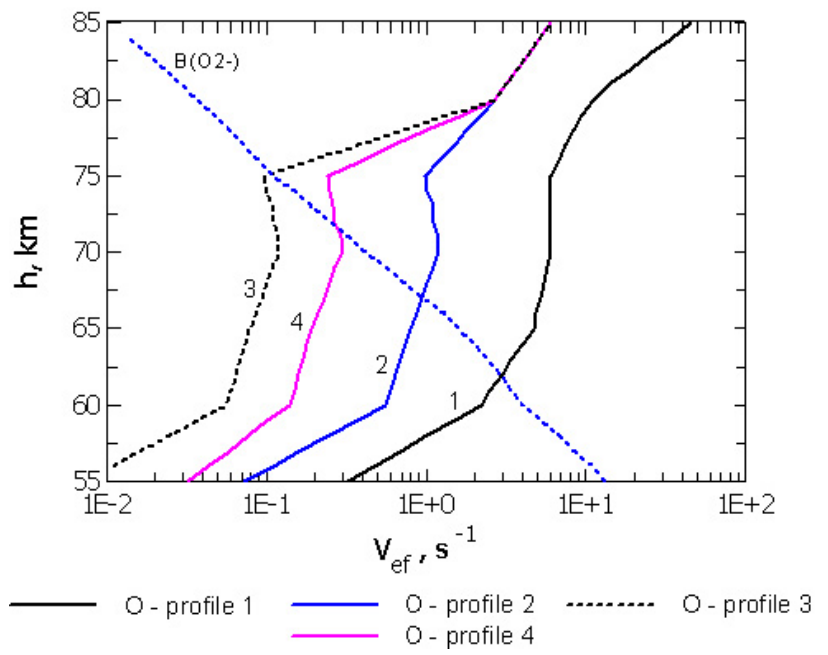

Fig. 5. Height profiles of reaction efficiencies. The curve $\mathrm{B}\left(\mathrm{O}_{2}^{-}\right)$ is the efficiency of the reaction path forming complex negative ions from $\mathrm{O}_{2}^{-}$ion. Curves 1-4 are efficiencies of associative detachment reaction: $\mathrm{O}_{2}^{-}+\mathrm{O} \rightarrow \mathrm{O}_{3}+e$ based on O-profiles 1-4.

They can initiate a complicated series of reactions with neutral constituents to produce a variety of negative ions, in particular $\mathrm{O}_{3}^{-}, \mathrm{O}_{4}^{-}, \mathrm{CO}_{2}^{-}, \mathrm{CO}_{4}^{-}$(Albritton, 1978). These ions are intermediate ions since they participate in fast ion-molecular reactions and rapidly appear and disappear. Concentrations of the intermediate ions are low; however their role in the formation of the major intermediate $\mathrm{CO}_{3}^{-}$ion and a stable $\mathrm{NO}_{3}^{-}$ ion, which is formed from $\mathrm{CO}_{3}^{-}$, is very important. Therefore in the scheme applied in this study the efficiency of the reaction chains forming the main intermediate ion $\mathrm{CO}_{3}^{-}$from the primary $\mathrm{O}_{2}^{-}$and $\mathrm{O}^{-}$ions are substituted by the $\mathrm{B}\left(\mathrm{O}_{2}^{-}\right)$ and $\mathrm{B}\left(\mathrm{O}^{-}\right)$effective parameters which are determined by Eqs. (A4) and (A5) in the Appendix. The $\mathrm{CO}_{3}^{-}$ion participates in the formation of the $\mathrm{NO}_{3}^{-}$ion via the reaction:

$\mathrm{CO}_{3}^{-}+\mathrm{NO}_{2} \rightarrow \mathrm{NO}_{3}^{-}+\mathrm{CO}_{2}$

The final ion $\mathrm{NO}_{3}^{-}$is stable in relation to atomic oxygen (Albritton, 1978). It disappears mainly in the ion-ion recombination reactions with positive ions.

On the other hand, the $\mathrm{CO}_{3}^{-}$ion disappears through photodissociation and photodetachment, as well as due to a rapid conversion to $\mathrm{O}_{2}^{-}$in a reaction with atomic oxygen:

$\mathrm{CO}_{3}^{-}+\mathrm{O} \rightarrow \mathrm{O}_{2}^{-}+\mathrm{CO}_{2}$

Thus atomic oxygen is a component which is able to convert the complex negative $\mathrm{CO}_{3}^{-}$ion into a simple $\mathrm{O}_{2}^{-}$ion; the latter disappearing through associative detachment

$\mathrm{O}_{2}^{-}+\mathrm{O} \rightarrow \mathrm{O}_{3}+e$

The efficiency of the path forming complex negative ions from the $\mathrm{O}_{2}^{-}$ion $\left(\mathrm{B}\left(\mathrm{O}_{2}^{-}\right)\right.$, defined in Eq. $\left.\mathrm{A} 2\right)$, and the 
efficiency profiles of the associative detachment Reaction (19) based on O-profiles 1-4 are presented in Fig. 5.

It is seen that the $\mathrm{O}_{2}^{-}$ion is removed mainly through the formation of complex negative ions, up to a height, $h_{m}$, which depends on [O]. In the model with low [O], $h_{m}=72 \mathrm{~km}$ $\left(v_{e f}=0.25 \mathrm{~s}^{-1}\right)$ and $h_{m}=75 \mathrm{~km}\left(v_{e f}=0.11 \mathrm{~s}^{-1}\right)$, correspondingly for profiles 4 and 3; for high [O]: for [O]-profile $1, h_{m}=62 \mathrm{~km}\left(v_{e f}=3.0 \mathrm{~s}^{-1}\right)$ and for O-profile $2, h_{m}=66 \mathrm{~km}$ $\left(v_{e f}=0.96 \mathrm{~s}^{-1}\right)$. Thus under conditions of low concentration of atomic oxygen, associative-detachment Reaction (19) does not play a central role at altitudes below $72 \mathrm{~km}$. As a consequence low [O] leads to a high concentration of $\mathrm{CO}_{3}^{-}$ and $\mathrm{NO}_{3}^{-}$ions. However for high [O], Reaction (19) is important. It decreases the $\mathrm{O}_{2}^{-}$-concentration and as a result can significantly alter the efficiency of the reaction path:

$\mathrm{O}_{2}^{-} \rightarrow \mathrm{CO}_{3}^{-} \rightarrow \mathrm{NO}_{3}^{-}$

at altitudes above $60 \mathrm{~km}$. The influence of the atomic oxygen concentration on the height distribution of negative ions during the SPE is demonstrated in Fig. 6 (upper panel).

A change of atomic oxygen concentration leads to a redistribution of the ion species abundance at the mesospheric altitudes (as in the case with positive ions).

In the model with low values of [O], the concentration of the intermediate $\mathrm{CO}_{3}^{-}$ion is much higher than in the model with high [O] values. As a result the $\mathrm{NO}_{3}^{-}$ion is a dominant ion up to $h_{m}\left(\mathrm{NO}_{3}^{-}\right) \approx 74 \mathrm{~km}$ and its concentration is about two orders of magnitude greater than $\mathrm{CO}_{3}^{-}$. Due to very weak efficiency of the reaction of associative detachment of electrons from ions $\mathrm{O}_{2}^{-}$and $\mathrm{O}^{-}$below $72 \mathrm{~km}$, the concentration of these species and the total concentration of negative ions are much more than in the model with high [O]. The $\mathrm{O}_{2}^{-}$ion becomes the major ion at altitudes above $h_{m}\left(\mathrm{NO}_{3}^{-}\right)=74 \mathrm{~km}$.

In the model with high [O], the $\mathrm{O}_{2}^{-}$and $\mathrm{O}^{-}$ions are the major negative ions above $h_{m}\left(\mathrm{NO}_{3}^{-}\right)$, which is about $65 \mathrm{~km}$ for O-profile 1.

It should be noted that, according to observations by Arnold et al. (1971) and to model studies by Wisemberg and Kockarts (1980), $\mathrm{NO}_{3}^{-}$is the major ion up to about $77-78 \mathrm{~km}$.

Thus the atomic oxygen concentration strongly influences the total negative ion density and the parameter $\lambda=\left[\mathrm{N}^{-}\right] /\left[\mathrm{N}_{e}\right]$ describing the ratio of the total negative ion density to the electron density (lower panel in Fig. 6). Both the $\lambda$ value and the transition height, $h_{\lambda=1}$, increase with decreasing [O], from $h_{\lambda=1}=61 \mathrm{~km}$ for O-profiles 1 up to $h_{\lambda=1}=66-67 \mathrm{~km}$ for O-profiles 4 and 3 .

As can be seen from Figs. 4 and 6, the [O] values represented by $\mathrm{O}$-profile 4 are critical values for the ion chemistry. The change from O-profile 4, to lower atomic oxygen concentration (O-profile 3), does not further affect the ion composition and does not alter noticeably the transition heights $h_{f+=1}$ and $h_{\lambda=1}$.
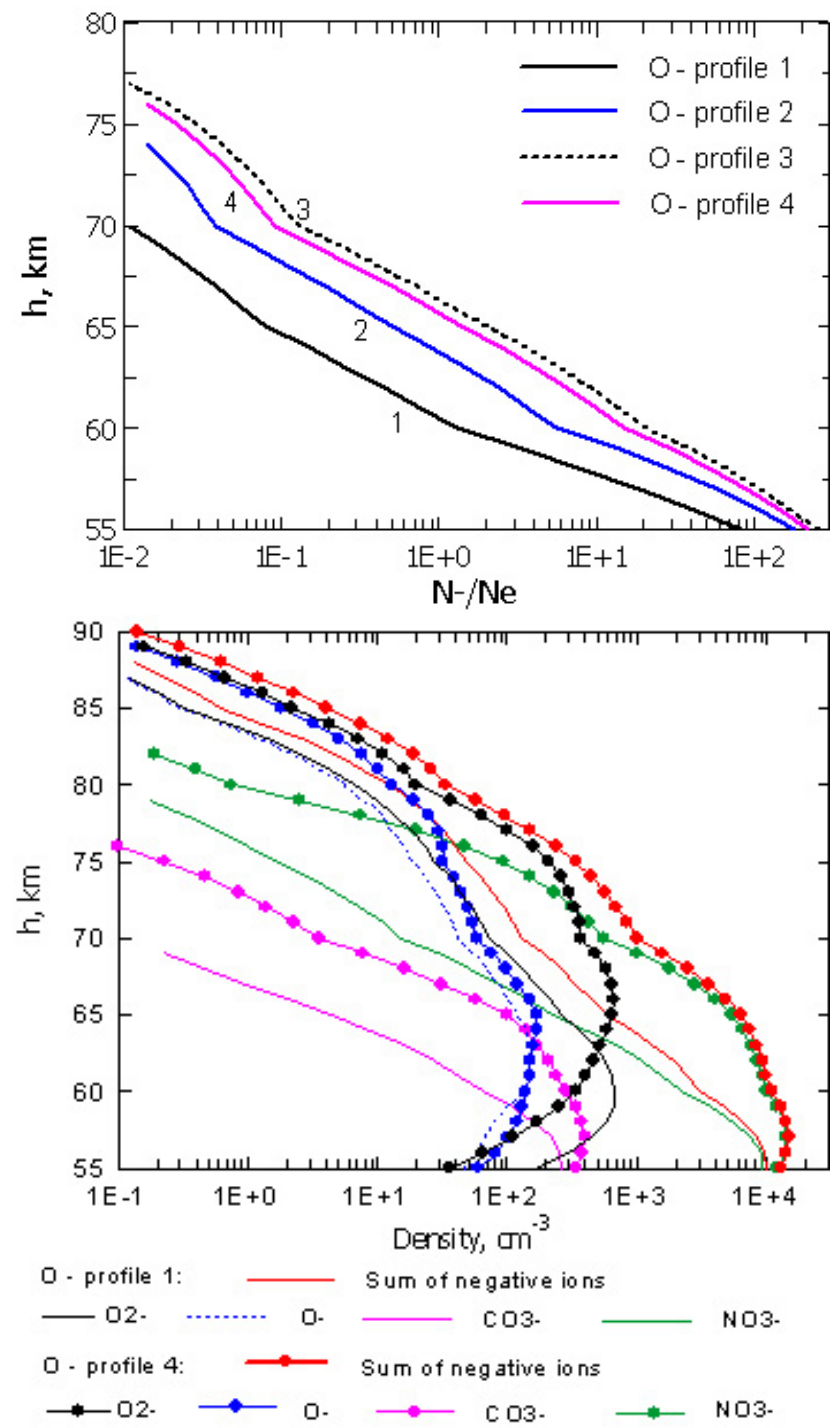

Fig. 6. Upper panel: Profiles of negative ions based on O-profiles 1 and 4 for 17 January 2005 at 09:50 UT. Lower panel: $\lambda(h)$-profiles based on O-profiles 1-4 for 17 January 2005 at 09:50 UT.

\subsection{Electron density}

Figure 7 demonstrates the role of the atomic oxygen concentration in the formation of the electron density profile for conditions corresponding to the SPE at 09:50 UT and 12:30 UT on 17 January 2005. The model profiles are compared with the $N_{e}(h)$-profiles measured by the incoherent scatter and partial reflection methods. First of all it should be noted that the electron density has been measured by the partial reflection method only inside a narrow height range, $55-65 \mathrm{~km}$. During the SPE, the EISCAT radar measured electron density at altitudes more than $60-65 \mathrm{~km}$. The EISCAT data calibration has been checked by comparing the $30 \mathrm{MHz}$ cosmic noise absorption estimated from the EISCAT electron 


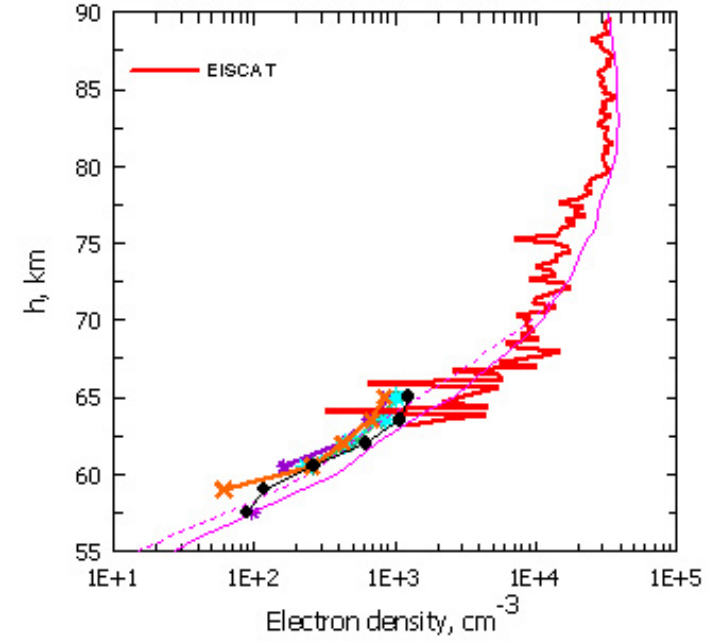

Model: $\longrightarrow 0$ - profile $4(X=92.3) \cdots \cdots$ - profile $4(X=94.5)$

Partial reflection method: $\longrightarrow 1228$ UT $\longrightarrow$ 1230 UT $\longrightarrow 1231$ UT $\longrightarrow-1232$ UT $\longrightarrow 1234$ UT

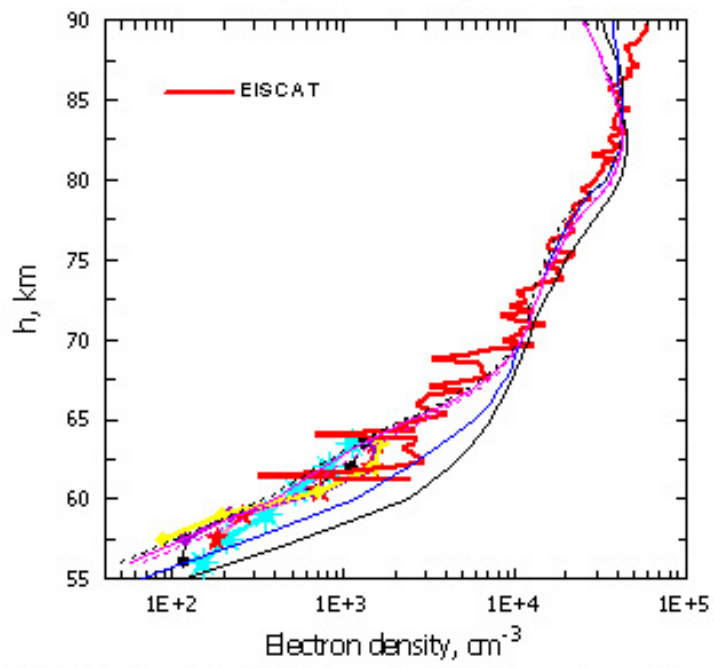

Model $(\alpha-90.7)$ : —o -prorlle 1 - 0 -prorle 2 - -..o-protle 3

— - protle $+(\alpha-90.7) \quad \ldots . .0-$ protle $+(\alpha-89.7)$

Partlal retlectbr me thod:

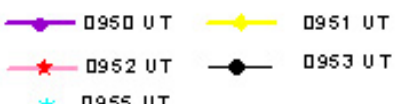

Fig. 7. Electron density profiles on 17 January 2005 at 09:50 UT and 12:30 UT.

Upper panel: the $\mathrm{N}_{e}$-profile measured with EISCAT radar $\left(\chi=90.7^{\circ}\right)$ is shown by red line; $\mathrm{N}_{e}$-profiles measured with the partial reflection method $\left(\chi=89.7^{\circ}\right)$ are shown by lines with symbols; model $\mathrm{N}_{e}$-profiles $\left(\chi=90.7^{\circ}\right)$ based on O-profiles $1-5$ are shown by solid lines without symbols.

Lower panel: the $\mathrm{N}_{e}$-profile measured with EISCAT radar $\left(\chi=92.4^{\circ}\right)$ is shown by red line; $\mathrm{N}_{e}$-profiles measured with the partial reflection method $\left(\chi=94.5^{\circ}\right)$ are shown by lines with symbols; model $\mathrm{N}_{e}$-profiles based on O-profile 4 are calculated for $\chi=92.3^{\circ}$ (solid line) and $\chi=94.5^{\circ}$ (dotted line). density with direct observations of absorption by the riometer located at Abisko (http://www.sgo.fi/Data/Riometer/ rioArchive.php). The calibration of the EISCAT electron density is found to be agree within $10 \%$. Zenith angles for both radars at 09:50 UT differ by $1^{\circ}\left(\chi=90.7^{\circ}\right.$ in Troms $\varnothing$ and $\chi=89.7^{\circ}$ in Murmansk). For such a difference in zenith angle both methods give approximately the same values of electron density at $60-65 \mathrm{~km}$. It should be noted that the model $N_{e}(h)$-profiles calculated for $\chi=90.7^{\circ}$ and $\chi=89.7^{\circ}$ demonstrate nearly the same values of electron density at all mesospheric altitudes. A maximum difference in the electron density at altitudes below $70 \mathrm{~km}$ does not exceed a factor of 1.15 .

As is seen in the upper panel of Fig. 7, the electron density calculated at 09:50 UT (for $\chi=90.7^{\circ}$ ) using the O-profiles 12 (which correspond to quiet conditions in the photochemical models), exceeds experimental $N_{e}$ values in the lower part of D-region (below the $68 \mathrm{~km}$ level) by factors of 3-5 for the O-profiles 1 and by about 2-3 times for the O-profile 2 . This can be explained mainly by too low concentrations of cluster ions, and therefore, too low associative detachment rates in the model. It is clear that the O-profile 1 , with very high [O], is not adequate. It gives high electron density at all mesospheric altitudes. High $N_{e}$ values in the height range of $72-80 \mathrm{~km}$ are due to a low concentration of the cluster ions, compared to the O-profiles 4 and 3. The electron density profiles calculated at 09:50 UT using the O-profiles 4 and 3 match each other and reproduce the form of the experimental $N_{e}(h)$-profiles. Calculated and measured $N_{e}$ values are, in these cases, the same or close at all mesospheric altitudes.

Zenith angles for both radars at 12:30 UT differ by $2^{\circ}$ ( $\chi=92.3^{\circ}$ in Troms $\varnothing$ and $\chi=94.5^{\circ}$ in Murmansk). The electron density profiles have been calculated on the basis of the O-profile 4 for both zenith angles. In this case the maximum difference between two model curves at heights below $70 \mathrm{~km}$, caused by the difference in zenith angles, is about factor of 1.5-1.6. It is due to a rapid decreasing of the atomic oxygen concentration with increasing of the solar zenith angle under twilight conditions. However, the both curves describe well electron density profiles measured at corresponding zenith angles. The $N_{e}(h)$-profile calculated for zenith angle $\chi=92.3^{\circ}$ (solid line in Fig. 7, lower panel) is close to the $N_{e}(h)$-profile measured with EISCAT radar at all mesospheric altitudes above $62 \mathrm{~km}$. Electron density calculated for $\chi=94.5^{\circ}$ (dotted line in Fig. 7, lower panel) reproduces the electron density at altitudes $57-65 \mathrm{~km}$ measured with the partial reflection technique.

Figure 8 further demonstrates a good agreement between the $N_{e}(h)$-profiles calculated at 13:30 UT $\left(\chi=95.0^{\circ}\right)$ and 14:00 UT $\left(\chi=96.7^{\circ}\right)$ on 17 January 2005 using the O-profiles 4 and 3 and experimental $N_{e}(h)$-profiles measured with the EISCAT radar.

Although not presented here, we have also used our ionchemical model to test the sensitivity of the electron density profile to likely changes in $\mathrm{NO}$ and $\mathrm{O}_{3}$. We find these to be of minor importance compared to the $\mathrm{O}$ profile. The influence 
of [NO] becomes important in the height range $\approx 70-85 \mathrm{~km}$, if, during SPE, [NO] is increased up to values exceeding $(1-2) \times 10^{8} \mathrm{~cm}^{-3}$. However, as it is seen from the results of the model study by Veronnen et al. (2002), increasing [NO] caused by solar protons is less than $10^{8} \mathrm{~cm}^{-3}$ even during the very strong SPE in October 2003. Variations in concentration of ozone are important at altitudse below $70 \mathrm{~km}$. However depletion of $\left[\mathrm{O}_{3}\right]$ due to an SPE does not exceed $50 \%$ (it is 20-30\%) (Seppala et al., 2004; Lopez-Piertas et al., 2005; Rochen et al., 2005; Verronen et al., 2005). The effect of such a decrease in ozone on the ion composition and electron density is very small.

Thus we can conclude that the atomic oxygen concentration described by the O-profile 4 at mesospheric altitudes represents the maximal $[\mathrm{O}]$-values consistent with the measured electron density during this winter-daytime SPE.

\section{Conclusions}

We have studied the influence of atomic oxygen concentration on the height distribution of the main positive and negative ions and on electron density in the mesosphere during the SPE on 17 January 2005 . We have shown by numerical modeling that the lower ionosphere structure strongly depends on the choice of the atomic oxygen profile. Alteration of the atomic oxygen concentration leads to a redistribution of the abundance of both positive and negative ion constituents, with changes in their total concentrations, and of transition heights $h_{f+=1}$ and $h_{\lambda=1}$. This results in changes in the electron density $\left(N_{e}=\mathrm{N}^{+}-\mathrm{N}^{-}\right)$and effective recombination coefficient $\alpha_{e f}$ :

$$
\begin{aligned}
\alpha_{e f} & =(1+\lambda)\left(\alpha_{d}+\lambda \alpha_{i}\right) \\
\alpha_{d} & =\frac{\alpha_{\mathrm{NO}^{+} \mathrm{O}_{2}^{+}}+f^{+} \alpha_{\mathrm{Cl}^{+}}}{1+f^{+}} \\
f^{+} & =\frac{\left[\mathrm{Cl}^{+}\right]}{\left[\mathrm{NO}^{+}\right]+\left[\mathrm{O}_{2}^{+}\right]}
\end{aligned}
$$

where the average recombination coefficient $\alpha_{d}$ depends on the parameter $f^{+} ; \alpha_{i}$ is the coefficient of ion-ion recombination.

For conditions with extra ionization produced by solar proton precipitation, we have used experimental data on the electron density, obtained with the incoherent scatter and partial reflection techniques, as the criterion for choosing the O-profile. As a result we can conclude that the atomic oxygen concentration described at local noon by the O-profile 4 (Fig. 1) reproduces the electron density and other ionospheric parameters during the SPE. The O-profile 4 is characterized by lower concentrations and by a rapid decreasing of the $\mathrm{O}$ concentration at altitudes between $80-75 \mathrm{~km}$ compared to Oprofiles 1 and 2 for quiet conditions. During the SPE a rapid decrease of the O-density below $80 \mathrm{~km}$ can be explained in terms of the photochemical lifetime of the atomic oxygen.
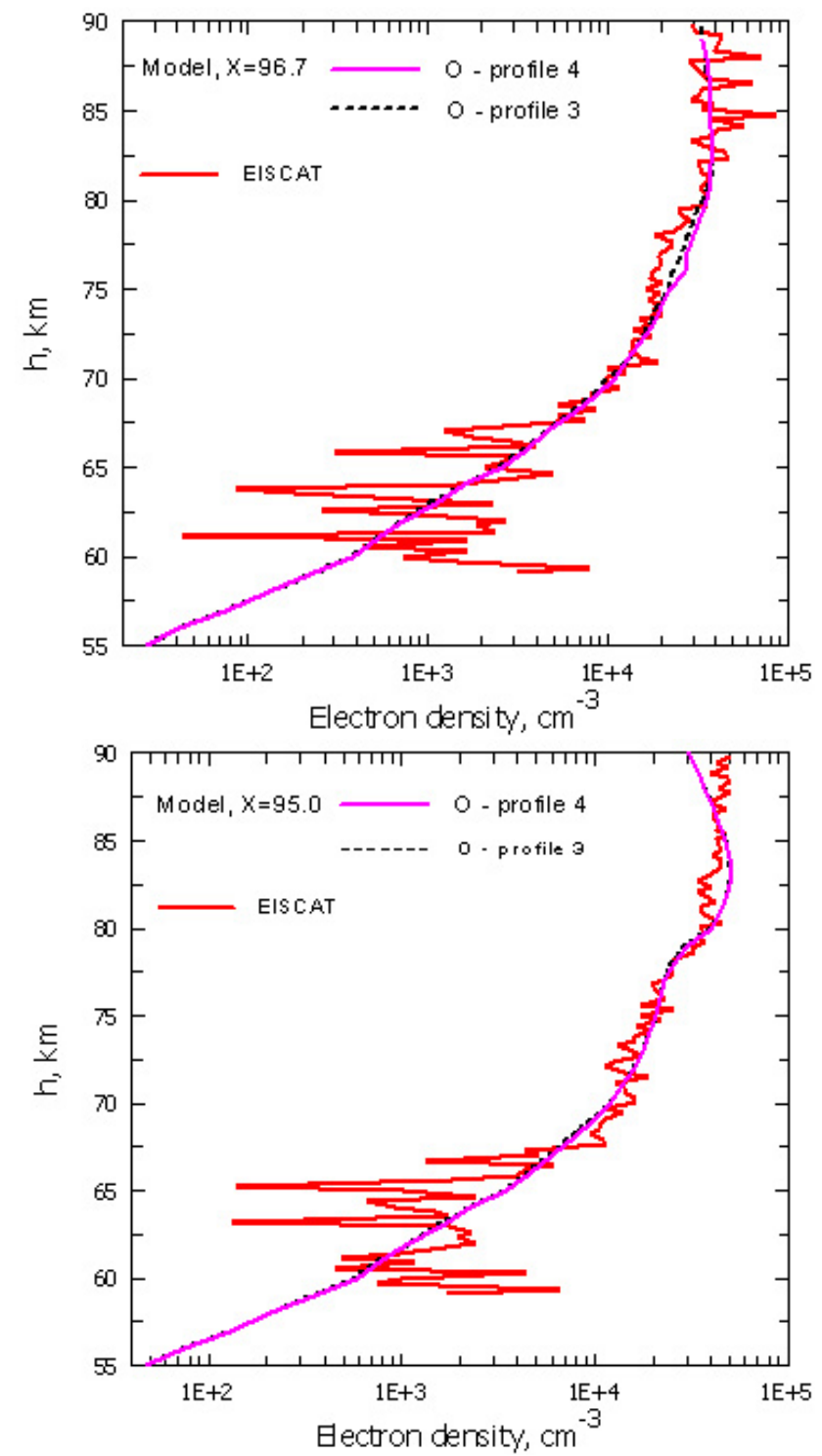

Fig. 8. Electron density profiles on 17 January 2005 at 13:30 UT and at 14:00 UT.

Upper panel: Model $\mathrm{N}_{e}$-profiles at 13:30 UT $\left(\chi=95.0^{\circ}\right)$ are based on O-profiles 4 and 3; $\mathrm{N}_{e}$-profile measured with EISCAT radar at 13:30 UT $\left(\chi=95.0^{\circ}\right)$ is shown by red line.

Lower panel: Model $\mathrm{N}_{e}$-profiles at 14:00 UT $\left(\chi=98.3^{\circ}\right)$ are based on O-profiles 4 and 3; $\mathrm{N}_{e}$-profile measured with EISCAT radar at 14:00 UT $\left(\chi=98.3^{\circ}\right)$ is shown by red line.

Atomic oxygen at mesospheric altitudes disappears fast due to reactions with odd hydrogen constituents $\mathrm{OH}$ and $\mathrm{HO}_{2}$, which concentrations are increased during the SPE.

Figure 9 shows changes in the O-density with changes in the solar zenith angle. The O-profile 4 (local noon) is shown here by the red line. The O-profiles at the various solar zenith angles (at 09:50 UT, 12:30 UT, 13:30 UT and 14:00 UT) are 


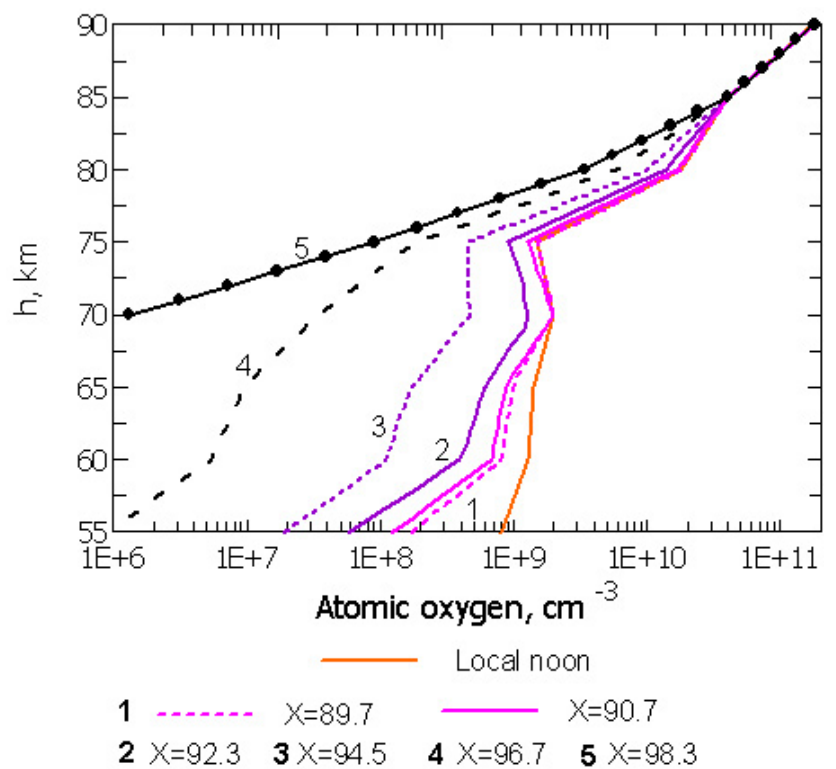

Fig. 9. The O-profiles which are consistent with the electron density profiles measured during winter SPE at various zenith angles. Red line is the O-profile at local noon.

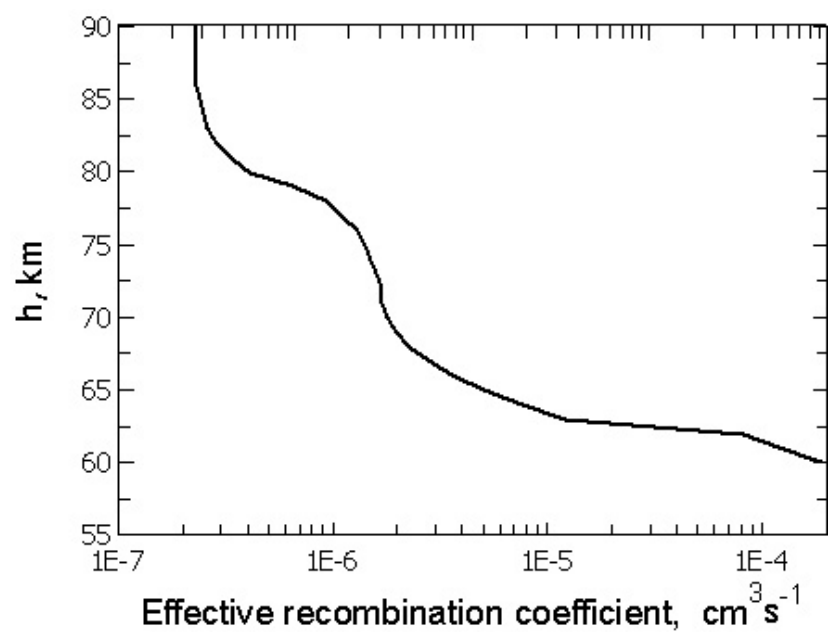

Fig. 10. Profiles of the effective recombination coefficient based on O-profiles 4 for 17 January 2005 at 09:50 UT.

presented by lines $1-5$. As it has been shown above (Figs. 7 and 8), all these O-profiles provide an appropriate behavior of the electron density profiles measured during winter SPE at appropriate solar zenith angles.

We have shown that, under conditions of low concentration of atomic oxygen during the SPE (in the model with the O-profile 4), the formation of cluster ions is the key process determining electron and ion densities at altitudes up to about $76-77 \mathrm{~km}$. The complex negative $\mathrm{CO}_{3}^{-}$ion is formed up to about $72-74 \mathrm{~km}$ and the final $\mathrm{NO}_{3}^{-}$ion, which is stable in relation to atomic oxygen, is the dominant negative ion up

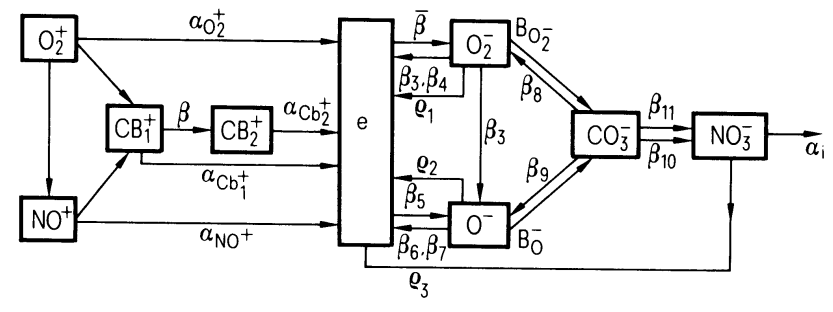

Fig. A1. Block diagram of the ion-chemical model of the D-region (Smirnova et al., 1988).

to about $74 \mathrm{~km}$. The transition heights between cluster ions and molecular ions, $h_{f+=1}$, and between negative ions and electron density, $h_{\lambda=1}$, are located at $77 \mathrm{~km}$ and $66 \mathrm{~km}$, respectively.

Finally, in Fig. 10 we present the height distribution of effective recombination coefficient calculated for the SPE on 17 January 2005 (near noon conditions). It is clear that, in the height range $\approx 68-77 \mathrm{~km}, \alpha_{e f}$ is determined by the dissociative recombination coefficient of the hydrated ion cluster family, with $\alpha \approx 1 \times 10^{-6} \mathrm{~cm}^{3} \mathrm{~s}^{-1}$. At altitudes above $80 \mathrm{~km}$ $\alpha_{e f}$ is determined by the dissociative recombination coefficients of $\mathrm{O}_{2}^{+}$and $\mathrm{NO}^{+}$ions. Below $67 \mathrm{~km}$ it is determined by the dissociative recombination coefficient of the proton hydrates $\mathrm{CB}_{2}^{+}$family and by the coefficient of ion-ion recombination between positive and negative ions.

\section{Appendix A}

\section{Ion chemistry model}

Figure $\mathrm{A} 1$ shows the reaction paths and reaction rates for the effective ions considered in the ion-chemistry model (from Smirnova et al., 1988). All effective rate coefficients are derived from analysis of detailed ion-chemical models (Reid, 1977; Chakrabarty et al., 1978; Arnold, 1980; Ferguson, 1974, 1976). These coefficients include the rates of the main ionic transformation processes and contain dependencies on neutral temperature $(\mathrm{T})$, density, humidity and the concentrations of minor neutral species such as $\mathrm{O}, \mathrm{O}_{3}, \mathrm{O}_{2}\left({ }^{1} \Delta g\right)$.

The efficiency of the family $\mathrm{CB}_{1}^{+}$ion cluster formation from the $\mathrm{NO}^{+}$ion is given by the expression:

$$
\begin{aligned}
\mathrm{B}_{\mathrm{NO}+}= & {\left[\mathrm{H}_{2} \mathrm{O}\right]\left\{r_{1}\left[\mathrm{~N}_{2}\right]+\frac{r_{2}\left[\mathrm{~N}_{2}\right]^{2} r_{4}}{C}+\frac{r_{6}}{r_{6}\left[\mathrm{H}_{2} \mathrm{O}\right]+r_{-5}\left[\mathrm{~N}_{2}\right]}\right.} \\
& \left.\left(r_{5}\left[\mathrm{CO}_{2}\right]\left[\mathrm{N}_{2}\right]+\frac{r_{2}\left[\mathrm{~N}_{2}\right]^{2} \cdot r_{3}\left[\mathrm{CO}_{2}\right]}{C}\right)\right\}
\end{aligned}
$$

where $r_{n}$ are rate constants (see Table A1), $C=r_{-2}\left[\mathrm{~N}_{2}\right]+r_{3}\left[\mathrm{CO}_{2}\right]+r_{4}\left[\mathrm{H}_{2} \mathrm{O}\right], \quad$ and $r_{1}, \quad r_{2}, \quad r_{-2}, \quad r_{5}$, $r_{-5}=f(T)$.

The efficiency $\mathrm{B}_{\mathrm{NO}+}$ of the channel: $\mathrm{NO}^{+} \rightarrow \mathrm{CB}_{1}^{+}$has strong inverse temperature dependence, $\mathrm{B}_{\mathrm{NO}+} \propto T^{-13.9}$ in the 
Table A1. Rate constants for positive ion reactions in the reaction path $\mathrm{NO}^{+} \rightarrow \mathrm{CB}_{1}^{+}$family and for recombination rates $\alpha\left(\mathrm{NO}^{+}\right)$and $\alpha_{i}\left(\mathrm{NO}^{+}\right)$.

\begin{tabular}{ll}
\hline $\mathrm{NO}^{+}+\mathrm{H}_{2} \mathrm{O}+\mathrm{N}_{2} \rightarrow \mathrm{NO}^{+} . \mathrm{H}_{2} \mathrm{O}+\mathrm{N}_{2}$ & $r_{1}=1.8 \times 10^{-28}(300 / T)^{4.7}$ \\
$\mathrm{NO}^{+}+2 \mathrm{~N}_{2} \rightarrow \mathrm{NO}^{+} . \mathrm{N}_{2}+\mathrm{N}_{2}$ & $r_{2}=2.0 \times 10^{-31}(300 / T)^{4.4}$ \\
$\mathrm{NO}^{+} . \mathrm{N}_{2}+\mathrm{N}_{2} \rightarrow \mathrm{NO}^{+}+2 \mathrm{~N}_{2}$ & $r_{-2}=1.5 \times 10^{6} T^{-5.4} \exp (-2450 / T)$ \\
$\mathrm{NO}^{+} .\left(\mathrm{H}_{2} \mathrm{O}\right) . \mathrm{N}_{2}+\mathrm{N}_{2}$ & $r_{-2}=1.5 \times 10^{6} T^{-5.4} \mathrm{exp}(-2450 / T)$ \\
$\rightarrow \mathrm{NO}^{+} . \mathrm{H}_{2} \mathrm{O}+\mathrm{N}_{2}+\mathrm{N}_{2}$ & \\
$\mathrm{NO}^{+} . \mathrm{N}_{2}+\mathrm{CO}_{2} \rightarrow \mathrm{NO}^{+} . \mathrm{CO}_{2}+\mathrm{N}_{2}$ & $r_{3}=1.0 \times 10^{-9}$ \\
$\mathrm{NO}^{+} . \mathrm{CO}_{2}+\mathrm{H}_{2} \mathrm{O} \rightarrow \mathrm{NO}^{+} . \mathrm{H}_{2} \mathrm{O}+\mathrm{CO}_{2}$ & $r_{4}=1.0 \times 10^{-9}$ \\
$\mathrm{NO}^{+} .\left(\mathrm{H}_{2} \mathrm{O}\right)_{n}+\mathrm{CO}_{2}+\mathrm{N}_{2}$ & $r_{5}=7.0 \times 10^{-30}(300 / T)^{3.0}$ \\
$\rightarrow \mathrm{NO}^{+} .\left(\mathrm{H}_{2} \mathrm{O}\right)_{n} \cdot \mathrm{CO}_{2}+\mathrm{N}_{2}$ & \\
$\mathrm{NO}^{+} . \mathrm{CO}_{2}+\mathrm{N}_{2} \rightarrow \mathrm{NO}^{+}+\mathrm{CO}_{2}+\mathrm{N}_{2}$ & $r_{-5}=3.1 \times 10^{4} T^{-4.0} \mathrm{exp}(-4590 / T)$ \\
$\mathrm{NO}^{+} .\left(\mathrm{H}_{2} \mathrm{O}\right)_{n} \cdot \mathrm{N}_{2}+\mathrm{H}_{2} \mathrm{O} \rightarrow$ & $r_{6}=1.0 \times 10^{-9}$ \\
$\mathrm{NO}^{+} .\left(\mathrm{H}_{2} \mathrm{O}\right)_{n+1}+\mathrm{N}_{2}$ & \\
$\mathrm{NO}^{+} .\left(\mathrm{H}_{2} \mathrm{O}\right)_{n} . \mathrm{CO}_{2}+\mathrm{H}_{2} \mathrm{O}$ & $r_{6}=1.0 \times 10^{-9}$ \\
$\rightarrow \mathrm{NO}^{+} .\left(\mathrm{H}_{2} \mathrm{O}\right)_{n+1}+\mathrm{CO}_{2}$ & \\
$\mathrm{NO}^{+} .\left(\mathrm{H}_{2} \mathrm{O}\right)+\mathrm{H}_{2} \mathrm{O}_{+} \mathrm{N}_{2}$ & $r_{7}=1.0 \times 10^{-27}(300 / T)^{4.4}$ \\
$\rightarrow \mathrm{NO}^{+} .\left(\mathrm{H}_{2} \mathrm{O}\right)_{2}+\mathrm{N}_{2}$ & $k=1.0 \times 10^{-14}$ \\
$\mathrm{NO}^{+} .\left(\mathrm{H}_{2} \mathrm{O}\right)+\mathrm{O} \rightarrow \mathrm{NO}_{2}^{+}+\mathrm{H}_{2} \mathrm{O}$ & $\alpha\left(\mathrm{NO}^{+}\right)=4.0 \times 10^{-7}(300 / T)$ \\
$\alpha\left[\mathrm{N}_{e}\right]\left[\mathrm{NO}^{+}\right]$ & $\alpha_{i}=6.8 \times 10^{-7} T^{-0.4}$ \\
$\alpha\left[\mathrm{N}^{-}\right]\left[\mathrm{NO}^{+}\right]$ & \\
\hline
\end{tabular}

Table A2. Rate constants for main ion reactions in the reaction path $\mathrm{O}_{2}^{+} \rightarrow \mathrm{CB}_{1}^{+}$and the recombination coefficients $\alpha\left(\mathrm{O}_{2}^{+}\right)$and $\alpha_{i}\left(\mathrm{O}_{2}^{+}\right)$.

\begin{tabular}{ll}
\hline $\mathrm{O}_{2}^{+}+\mathrm{O}_{2}+\mathrm{O}_{2} \rightarrow \mathrm{O}_{4}^{+}+\mathrm{O}_{2}$ & $\mathrm{~K}_{1}=2.4 \times 10^{-30}(300 / T)^{3.2}$ \\
$\mathrm{O}_{4}^{+}+\mathrm{O}_{2} \rightarrow \mathrm{O}_{2}^{+}+2 \mathrm{O}_{2}$ & $\mathrm{~K}_{-1}=1.8 \times 10^{-5}(300 / T)^{4.2} \exp (-5000 / T)$ \\
$\mathrm{O}_{4}^{+}+\mathrm{O} \rightarrow \mathrm{O}_{2}^{+}+\mathrm{O}_{3}$ & $\mathrm{~K}_{2}=3.0 \times 10^{-10}$ \\
$\mathrm{O}_{4}^{+}+\mathrm{O}_{2}\left({ }^{1} \Delta_{g}\right) \rightarrow \mathrm{O}_{2}^{+}+2 \mathrm{O}_{2}$ & $\mathrm{~K}_{3}=1.0 \times 10^{-10}$ \\
$\mathrm{O}_{4}^{+}+\mathrm{H}_{2} \mathrm{O} \rightarrow \mathrm{O}_{2}^{+} \cdot \mathrm{H}_{2} \mathrm{O}+\mathrm{O}_{2}$ & $\mathrm{~K}_{4}=2.2 \times 10^{-9}$ \\
$\mathrm{O}_{2}^{+}+\mathrm{NO} \rightarrow \mathrm{NO}^{+}+\mathrm{O}_{2}$ & $\mathrm{~K}_{5}=4.4 \times 10^{-10}$ \\
$\mathrm{O}_{2}^{+}+\mathrm{N}_{2} \rightarrow \mathrm{NO}^{+}+\mathrm{NO}$ & $\mathrm{K}_{6}=1.0 \times 10^{-17}$ \\
$\mathrm{O}_{2}^{+}+\mathrm{N}_{2}+\mathrm{N}_{2} \rightarrow \mathrm{O}_{2}^{+} \cdot \mathrm{N}_{2}+\mathrm{N}_{2}$ & $v_{1}=8.0 \times 10^{-31}(300 / T)^{4.4}$ \\
$\alpha\left[\mathrm{N}_{e}\right]\left[\mathrm{O}_{2}^{+}\right]$ & $\alpha\left(\mathrm{O}_{2}^{+}\right)=2.0 \times 10^{-7}(300 / T)$ \\
$\alpha_{i}\left[\mathrm{~N}^{-}\right]\left[\mathrm{O}_{2}^{+}\right]$ & $\alpha_{i}=6.8 \times 10^{-7} T-0.4$ \\
\hline
\end{tabular}

range $120-180 \mathrm{~K}$ and $\mathrm{B}_{\mathrm{NO}+} \propto T^{-20}$ in the range $180-230 \mathrm{~K}$, which is typical for the winter mesosphere at high latitudes.

The efficiency of the reaction path $\mathrm{O}_{2}^{+} \rightarrow \mathrm{CB}_{1}^{+}$family is determined by the expression:

$\mathrm{B}_{\mathrm{O}_{2}^{+}}=\frac{K_{1}\left[\mathrm{O}_{2}\right]^{2}+v_{1}\left[\mathrm{~N}_{2}\right]^{2}}{\left\{\left(K_{2}[\mathrm{O}]+K_{3}\left[\mathrm{O}_{2}\left({ }^{1} \Delta g\right)\right]+K_{-1}\left[\mathrm{O}_{2}\right]\right) / K_{4}\left[\mathrm{H}_{2} \mathrm{O}\right]\right\}+1}$ where $K_{n}$ are reaction rates as given in Table A2, and $K_{1}, v_{1}$, $K_{-1}=f(T)$.

This has been derived from a detailed scheme for the reaction path, which includes, not only those processes usually considered, but also an additional $\mathrm{CB}_{1}^{+}$formation path via the cluster ion $\mathrm{O}_{2}^{+} \cdot \mathrm{N}_{2}$ and the thermal decomposition of $\mathrm{O}_{4}^{+}$. 
Table A3. Rate constants for negative ion reactions.

\begin{tabular}{ll}
\hline$e+\mathrm{O}_{2}+\mathrm{O}_{2}=\mathrm{O}_{2}^{-}+\mathrm{O}_{2}$ & $\beta_{1}=1.4 \times 10^{-29}(300 / T) \exp (-600 / T)$ \\
$e+\mathrm{O}_{2}+\mathrm{N}_{2}=\mathrm{O}_{2}^{-}+\mathrm{N}_{2}$ & $\beta_{2}=1.0 \times 10^{-31}$ \\
$\mathrm{O}_{2}^{-}+\mathrm{O}\left({ }^{3} \mathrm{P}\right)=\mathrm{O}_{3}+e$ & $\beta_{3}=1.5 \times 10^{-10}$ \\
$\mathrm{O}_{2}^{-}+\mathrm{O}_{2}\left({ }^{1} \Delta_{g}\right) \rightarrow \mathrm{O}_{2}+\mathrm{O}_{2}+e$ & $\beta_{4}=2.0 \times 10^{-10}$ \\
$e+\mathrm{O}_{3} \rightarrow \mathrm{O}^{-}+\mathrm{O}_{2}$ & $\beta_{5}=9.1 \times 10^{-12}(300 / T)^{-1.46}$ \\
$\mathrm{O}^{-}+\mathrm{O}=\mathrm{O}_{2}+e$ & $\beta_{6}=1.9 \times 10^{-10}$ \\
$\mathrm{O}^{-}+\mathrm{O}_{2}\left({ }^{1} \Delta_{g}\right) \rightarrow \mathrm{O}_{3}+e$ & $\beta_{7}=2.0 \times 10^{-10}$ \\
$\mathrm{CO}_{3}^{-}+\mathrm{O}\left({ }^{3} \mathrm{P}\right) \rightarrow \mathrm{O}_{2}^{-}+\mathrm{CO}_{2}$ & $\beta_{8}=1.1 \times 10^{-10}$ \\
$\mathrm{CO}_{3}^{-}+h v=\mathrm{O}^{-}+\mathrm{CO}_{2}$ & $\beta_{9}=0.15$ \\
$\mathrm{CO}_{3}^{-}+\mathrm{NO}^{-} \mathrm{NO}_{2}^{-}+\mathrm{CO}_{2}$ & $\beta_{10}=1.1 \times 10^{-10}$ \\
$\mathrm{CO}_{3}^{-}+\mathrm{NO}_{2} \rightarrow \mathrm{NO}_{3}^{-}+\mathrm{CO}_{2}$ & $\beta_{11}=2.0 \times 10^{-10}$ \\
$\mathrm{O}_{2}^{-}+\mathrm{O}_{2}+\mathrm{O}_{2} \rightarrow \mathrm{O}_{4}^{-}+\mathrm{O}_{2}$ & $\beta_{12}=4.0 \times 10^{-31}(300 / T)^{5.0}$ \\
$\mathrm{O}_{2}^{-}+\mathrm{O}_{2}+\mathrm{CO}_{2} \rightarrow \mathrm{CO}_{4}^{-}+\mathrm{O}_{2}$ & $\beta_{13}=2.0 \times 10^{-29}(300 / T)^{5.0}$ \\
$\mathrm{O}_{2}^{-}+\mathrm{O}_{3} \rightarrow \mathrm{O}_{3}^{-}+\mathrm{O}_{2}$ & $\beta_{14}=6.0 \times 10^{-10}$ \\
$\mathrm{O}^{-}+\mathrm{O}_{2}+\mathrm{O}_{2} \rightarrow \mathrm{O}_{3}^{-}+\mathrm{O}_{2}$ & $\beta_{15}=9.0 \times 10^{-31}(300 / T)^{5.0}$ \\
$\mathrm{O}^{-}+\mathrm{CO}_{2}+\mathrm{O}_{2} \rightarrow \mathrm{CO}_{3}^{-}+\mathrm{O}_{2}$ & $\beta_{16}=3.1 \times 10^{-28}(300 / T)^{5.0}$ \\
$\mathrm{O}^{-}+\mathrm{O}_{3} \rightarrow \mathrm{O}_{3}^{-}+\mathrm{O}$ & $\beta_{17}=5.3 \times 10^{-10}$ \\
$\mathrm{O}_{2}^{-}+h \nu \rightarrow e+\mathrm{O}_{2}$ & $\rho_{1}=0.33 \mathrm{~s}^{-1}$ \\
$\mathrm{O}^{-}+h \nu \rightarrow e+\mathrm{O}^{-}+h$ & $\rho_{2}=1.4 \mathrm{~s}-1$ \\
$\mathrm{NO}_{3}^{-}+h \nu=e+\mathrm{NO}_{3}$ & $\rho_{3}=1.5 \times 10^{-3} \mathrm{~s}-1$ \\
$\alpha_{i} \mathrm{~N}^{+}\left[\mathrm{O}_{2}^{-}\right]$ & $\alpha_{i}=6.8 \times 10^{-7} T^{-0.4}$ \\
$\alpha_{i} \mathrm{~N}^{+}\left[\mathrm{O}^{-}\right]$ & $\alpha_{i}=6.8 \times 10^{-7} T^{-0.4}$ \\
$\alpha_{i} \mathrm{~N}^{+}\left[\mathrm{CO}_{3}^{-}\right]$ & $\alpha_{i}=6.8 \times 10^{-7} T^{-0.4}$ \\
\hline &
\end{tabular}

The $\mathrm{B}_{\mathrm{O} 2+}$ rate is proportional to $T^{-4.4}$ and depends on the $\mathrm{H}_{2} \mathrm{O}$ and $\mathrm{O}$ concentrations at any temperature.

The more complicated cluster ions Cluster ${ }_{2}^{+}\left(\right.$or $\mathrm{CB}_{2}^{+}$) are formed from $\mathrm{CB}_{1}^{+}$with rate $\beta$ :

$$
\beta=10^{-27}(300 / T)^{4.4}\left[\mathrm{H}_{2} \mathrm{O}\right]\left[\mathrm{N}_{2}\right]
$$

This has been estimated from consideration of the formation rates of cluster ions of $\mathrm{NO}^{+}\left(\mathrm{H}_{2} \mathrm{O}\right)_{n}$ and $\mathrm{H}^{+}\left(\mathrm{H}_{2} \mathrm{O}\right)_{n}$ types and from comparison of the bond energies of the corresponding intermediate cluster ions.

The intermediate negative ions $\mathrm{CO}_{3}^{-}$are formed from the primary ions $\mathrm{O}_{2}^{-}$and $\mathrm{O}^{-}$. Efficiencies of the different paths corresponding to Eqs. (15a) and (15b) are described by the effective coefficients $\mathrm{B}_{\mathrm{O}_{2}-}$ and $\mathrm{B}_{\mathrm{O}_{-}}$, respectively:

$$
\begin{aligned}
& \mathrm{B}_{\mathrm{O} 2}-=\beta_{12}\left[\mathrm{O}_{2}\right]^{2}+\beta_{13}\left[\mathrm{O}_{2}\right]\left[\mathrm{CO}_{2}\right]+\beta_{14}\left[\mathrm{O}_{3}\right] \\
& \mathrm{B}_{\mathrm{O}-}=\beta_{15}\left[\mathrm{O}_{2}\right]^{2}+\beta_{16}\left[\mathrm{O}_{2}\right]\left[\mathrm{CO}_{2}\right]+\beta_{17}\left[\mathrm{O}_{3}\right]
\end{aligned}
$$

Acknowledgements. This research is partly supported by the RFFI grant No. 07-05-00012 and by the Swedish Academy of Sciences (KVA). EISCAT is an international association supported by the research councils of Finland (SA), France (CNRS), the Federal Republic of Germany (MPG), Japan (NIPR), Norway (NFR), Sweden (VR) and the United Kingdom (PPARC).

Topical Editor M. Pinnock thanks M. Friedrich and L.-A. McKinnel for their help in evaluating this paper.

\section{References}

Albritton, D. L.: Ion-neutral reaction-rate constants measured in flow reactions through 1977, At. Data Nucl. Tables, 22, 1-101, 1978.

Aikin, A. C. and Goldberg, R. A.: Distribution of $\mathrm{NO}_{2}^{+}$in the lower ionosphere, J. Geophys. Res., 78(7), 1229-1231, 1973.

Anderson, L. G.: Atmospheric chemical kinetic data survey, Rev. Geophys. Space Phys., 14(2), 151-171, 1976.

Arnold, F. and Krankowsky, D. F.: Negative ions in the lower ionosphere. A comparison of a model computation and a massspectrometric measurements, J. Atmos. Terr. Phys., 33, 16931702, 1971.

Arnold, F.: The middle atmosphere ionized component, Proc. ESA Symposium on rocket and balloon programmers, Bournemouth, ESA-SP 152, 479-496, 1980.

Chakrabarty, D. K., Chakrabarty, P., and Witt, G.: An attempt to identify the obscured paths of water positive ions build-up in the D-region, J. Atmos. Terr. Phys., 40(4), 437-442, 1978.

Dickinson, P. H. G., Bain, W. C., Thomas, E. R., Wiliams, D. B., Jenkins, D. B., and Twiddy, N. D.: The determination of the atomic oxygen concentration and associated parameters in the lowe ionosphere, Proc. R. Soc. Lond. A., 369, 379-408, 1980.

Ferguson, E. E.: Laboratory measurements of ionospheric ionmolecule reaction rates, Rev. Geophys. Space Phys., 12, 703713, 1974.

Ferguson, E. E.: D-region ion chemistry, Rev. Geophys. Space Phys., 9, 997-1008, 1976.

Frederick, J. E.: Solar corpuscular emission and neutral chemistry in the earth's middle atmosphere, J. Geophys. Res., 81(19), 3179-3186, 1976.

Friedrich, M., Egger, G., McKinnell, L. A., and Belova, E.: Perturbations in EISCAT electron density visualized by normalization, Adv. Space Res., 38, 2413-2417, 2006.

Gumbel, J., Murtagh, D. P., Espy, P. J., Witt, G., and Schmidlin, F. J.: Odd oxygen measurements during the Noctilucent Cloud 93 rocket campaign, J. Geophys. Res., A., 103, 23 399-23 414, 1998.

Heath, D. F., Krueger, A. J., and Crutzen, P. J.: Solar proton event: influence on stratospheric ozone, Science, 197, 886-889, 1977.

Hedin, A. E.: Extension of the MSIS thermosphere model into the middle and lower atmosphere, J. Geophys. Res., 96, 1159-1172, 1991.

Jackman, C. H., Cerniglia, M. C., Nielsen, J. E., Allen, D. J., Zawodny, J. M., McPeter, R. D., Douglas, A. R., Rosenfield, J. E., and Hood, R. B.: Two-dimensional and three-dimensional model simulations, measurements and interpretation of the October 1989 solar proton events on the middle atmosphere, J. Geophys. Res., 100, $11641-11660,1995$.

Jackman, C. H., DeLand, M. T., Labow, G. J., Fleming, E. L., Weisenstein, D. K., Ko, M. K. W., Sinnhuber, M., and Russel, J. M.: Neutral atmosphere influences of the solar proton events in October-November 2003, J. Geophys. Res., 110, A09S27, doi:10.1029/2004JA010888, 2005.

Keneshea, T. J., Zimmerman, S. P., and George, J. D.: The latitudinal variation of major and minor neutral species in the upper atmosphere, Space Res., XII, 695-709, 1972.

Kirkwood, S. and Osepian, A.: Quantitative studies of energetic particle precipitation using incoherent scatter radar, J. Geomag. Geoelectr., 47, 783-799, 1995. 
Kozlov, S. I., Smirnova, N. V., and Vlaskov, V. A.: Specialized aeronomic model for investigations of an artificial modification of the middle atmosphere and lower ionosphere. 1. Requirements for the model and its basic construction principles, Kosmicheskie Issledovania, 26(5), 738-745, 1988.

Lopez-Piertas, M., Funke, B., Gil-Lopez, S., von Clarmann, T., Stiller, G.P., Hopfner, M., Kellmann, S., Fischer, H., and Jackman, C. H.: Observations of NO enhancement and ozone depletion in the Northern and Southern hemispheres after the OctoberNovember 2003 solar proton events, J. Geophys. Res., 110, A09S43, doi:10.1029/2005JA011050, 2005.

Maharaj-Sharma, R. and Shepherd, G. G.: Solar variability of the daytime atomic oxygen $\mathrm{O}\left({ }^{1} \mathrm{~S}\right)$ emission in the middle and lower thermosphere, J. Geophys. Res., 109, A03303, doi:10.1029/2003JA010183, 2004.

McKinnell, L. A. and Friedrich, M.: A neural network based ionospheric model for the auroral zone, J. Atmos. Sol. Terr. Phys., 69(12), 1459-1470, doi:10.1016/j.jastp.2007.05.003, 2007.

McPeters, R. D. and Jackman, C. H.: The response of ozone to solar proton events during solar cycle 21: The observations, J. Geophys. Res., 90, 7945-7954, 1985.

Murray, B. J. and Plane, J. M. C.: Modelling the impact of noctilucent cloud formation on atomic oxygen and other minor constituents of the summer mesosphere, Atmos. Chem. Phys., 5, 1027-1038, 2005,

http://www.atmos-chem-phys.net/5/1027/2005/.

Nygrén, T.: Introduction to incoherent scatter measurements, INVERS Oy, Sodankyla, Finland, 1996.

Ogawa, T. and Shimazaki, T.: Diurnal variations of odd nitrogen and ionic densities in the mesosphere and lower thermosphere: simultaneous solution of photochemical-diffusive equations, J. Geophys. Res., 80(28), 3945-3960, 1975.

Osepian, A. and Smirnova, N.: Modelling of absorption layer during absorption events, J. Atmos. Sol. Terr. Phys., 59(8), 951-960, 1997.

Porter, H. S., Jackman, C. H., and Green, A. E. S.: Efficiencies for production of atomic nitrogen and oxygen by relativistic proton impact in air, J. Chem. Phys., 65, 154-165, 1976.

Reid, G. C.: The production of water cluster positive ions in the quiet daytime D-region, Planet. Space Sci., 25(3), 275-290, 1977.

Reid, G. C., Solomon, S., and Garcia, R. R.: Response of the middle atmosphere to the solar proton events of August-December, 1989, Geophys. Res. Lett., 18(6), 1019-1022, 1991.

Rochen, G., von Savigny, C., Sinnhuber, M., Llewellyn, E. J., Kaiser, J. W., Jackman, C. H., Kallenrode, M.-B., Schroter, J., Eichmann, K.-U., Bowensmann, H., and Burrows, J. P.: Ozone depletion during solar proton events of October/November 2003 as seen by SCIAMACHY., J. Geophys. Res., 110, A09S39, doi:10.1029/2004JA010984, 2005.

Russell, J. P., Lowe, R. P., and Ward, W. E.: Atomic oxygen annual and semi-annual oscillations in the mesopause region for mid and equatorial latitudes, J. Atmos. Sol. Terr. Phys., 66, 451461, 2004.

Russell, J. P., Ward, W. E., Lowe, R. P., Roble, R. G., Shepherd, G. G., and Solheim, B. H.: Atomic oxygen profiles $(80-115 \mathrm{~km})$ derived from WINDII/UARS measurements of the hydroxyl and greenline airglow II: Local time-latitude dependence, J. Geophys. Res., 110, D15305, doi:10.1029/2004JD005570, 2005.
Seppala, A., Verronen, P. T., Kyrola, E., Hassinen, S., Blackman, L., Houchecorne, A., Bertaux, J. L., and Fussen, D.: Solar proton events of October-November 2003: Ozone depletion in the northen hemisphere polar winter as seen by GOMOS/Envisat, Geophys. Res. Lett., 31, L19107, doi:10.1029/2004GL021042, 2004.

Shimazaki, T. and Laird, A. R.: Seasonal effect on distributions of minor constituents in the mesosphere and lower thermosphere, Radio Sci., 1, 23-43, 1972.

Smirnova, N. V., Ogloblina, O. F., and Vlaskov, V. A.: Modelling of the lower ionosphere, Pageoph., 127(2/3), 353-379, 1988.

Smirnova, N. V., Vlaskov, V. A., and Kozlov, S. I.: Specialized aeronomic model for investigations of an artificial modification of the middle atmosphere and lower ionosphere. 2. Comparison of the model results with experimental data, Kosmicheskie Issledovania, 28(1), 77-84, 1990 (in Russian).

Solomon, S., Rusch, D. W., Gerard, J. C., Reid, G. C., and Crutzen, P. J.: The effect of particle precipitation events on the neutral and ion chemistry of the middle atmosphere. II. Odd hydrogen, Planet. Space Sci., 29(8), 885-892, 1981.

Solomon, S., Reid, G. C., Rusch, D. W., and Thomas, R. J.: Mesospheric ozone depletion during the solar proton event of July 1982. Part 2. Comparison between theory and measurements, Geophys. Res. Lett., 10(4), 257-260, 1983.

Swider, W.: Reply to a comment on a letter by Swider W. Sources for $\mathrm{H}^{+}\left(\mathrm{H}_{2} \mathrm{O}\right)_{n}$ ions in the D-region, J. Geohys. Res., 77(10), 2000-2003, 1972.

Swider, W. and Keneshea, T. Y.: Decrease of ozone and atomic oxygen in the lower ionosphere during PCA event, Planet. Space Sci., 21(11), 1969-1973, 1973.

Thomas, L. and Bowman, M. R.: The diurnal variations of hydrogen and oxygen constituents in the mesosphere and lower thermosphere, J. Atmos. Terr. Phys., 34(11), 1843-1858, 1972.

Verronen, P. T., Turunen, E., Ulich, T., and Kyrola, E.: Modelling the effects of the October 1989 solar proton event on mesospheric odd nitrogen using a detailed ion and neutral chemistry model, Ann. Geophys., 20, 1967-1976, 2002, http://www.ann-geophys.net/20/1967/2002/.

Verronen, P. T., Seppala, A., Cliverd, M. A., Rodger, C. J., Kyrola, E., Enell, C. F., Ulich, T., and Turunen, E.: Diurnal variation of ozone depletion during the October-November 2003 solar proton event, J. Geophys. Res., 110, A09S32, doi:10.1029/2004JA010932, 2005.

Wisemberg, J. and Kockarts, G.: Negative ion chemistry in the terrestrial D region and signal flow graph theory, J. Geophys. Res., 85, 4642-4652, 1980.

Zadorozhny, A. M.: Diffusion-photochemical model of minor neutral constituents in the lower ionosphere, Edited by Science Akademy of USSR, Novosibirsk, 1982 (in Russian).

Zadorozhny, A. M., Tuchkov, G. A., Kikhtenko, V. N., Lastovicka, J., Boska, J., and Novak, A.: Nitric oxide and lower ionosphere quantities during solar particle events of October 1989 after rocket and ground-based measurements, J. Atmos. Terr. Phys., 54, 183-192, 1992. 